\section{UKCPR}

University of Kentucky

Center for

Poverty Research

\section{Discussion Paper Series}

DP 2016-01

ISSN: 1936-9379

\title{
Welfare Reform and the Intergenerational Transmission of Dependence
}

\author{
Robert Paul Hartley \\ Department of Economics \\ University of Kentucky \\ Carlos Lamarche \\ Department of Economics \\ University of Kentucky \\ James P. Ziliak \\ Department of Economics \\ University of Kentucky
}

Updated: September 2016

Preferred citation

Hartley, Robert Paul, Lamarche, Carlos, \& Ziliak, James P. 2016. Welfare Reform and the Intergenerational Transmission of Dependence. University of Kentucky Center for Poverty Research Discussion Paper Series, DP2016-01. Retrieved [Date] from http://www.ukcpr.org/research/discussion-papers.

Author correspondence

James P. Ziliak, University of Kentucky, Center for Poverty Research, Gatton Building Suite 234, 550 South Limestone Street, Lexington, KY 40506-0034; Email: jziliak@uky.edu 


\title{
Welfare Reform and the Intergenerational Transmission of Dependence*
}

\author{
Robert Paul Hartley \\ Department of Economics \\ University of Kentucky \\ Carlos Lamarche \\ Department of Economics \\ University of Kentucky \\ James P. Ziliak \\ Center for Poverty Research and \\ Department of Economics \\ University of Kentucky
}

September 2016

\footnotetext{
* Address correspondence to James P. Ziliak, University of Kentucky, Center for Poverty Research, Gatton Building Suite 234, 550 South Limestone St., Lexington, KY 40506-0034. Email: jziliak@uky.edu. We are grateful for comments from Anna Aizer, Richard Blundell, Chris Bollinger, Paul Devereux, Steven Durlauf, James Heckman, Hilary Hoynes, Mike Keane, Henrik Kleven, Robert Moffitt, Bill Neilson, Lara Shore-Sheppard, Jeff Smith, Lowell Taylor, Genia Toma, Marianne Wannamaker, and participants at the 2015 Summer School on Socioeconomic Opportunity, 2016 NBER Summer Institute, 2016 Barcelona GSE Summer Forum, 2016 Tennessee Empirical Applied Microeconomics Festival, the Institute for Fiscal Studies, Lancaster University, London School of Economics, Nuffield College (Oxford), University College Dublin, and VATT Institute for Economic Policy. The collection of data used in this study was partly supported by the National Institutes of Health under grant number R01 HD069609 and the National Science Foundation under award number 1157698.
} 


\begin{abstract}
We estimate the effect of welfare reform on the intergenerational transmission of welfare participation using a long panel of mother-daughter pairs over the survey period 19682013 in the Panel Study of Income Dynamics. Because states implemented welfare reform at different times starting in 1992, the cross-state variation over time permits us to quasi-experimentally separate out the effect of mothers' participation on daughters' welfare choice in the pre- and post-welfare reform periods. Our empirical framework also addresses potential issues in identifying a causal pathway from parent to child that arise from correlated unobservables in welfare decisions, misclassification error in survey reports, life-cycle differences in measuring the parent and child's age of welfare usage, and cross-state mobility. We find that a mother's welfare participation increased her daughter's odds of participation as an adult by around 25 to 35 percentage points, but that welfare reform attenuated this transmission by at least 50 percent, or at least 30 percent over the baseline odds of participation. However, when we broaden the definition of welfare received by the daughter to also include assistance from means-tested food or disability assistance, then the transmission from mother to daughter does not decrease after welfare reform. This seems to be a consequence of persistence in intergenerational poverty status.
\end{abstract}




\section{Introduction}

A fundamental goal of the landmark 1996 welfare reform in the United States was to eliminate the dependence of needy families on government assistance. This was premised in part on the belief that dependence is passed down from parent to child through knowledge and values, creating a "culture of welfare" across generations (Murray 1984; DeParle 2004; Haskins 2007). While this belief was bolstered by an empirical consensus documenting a positive intergenerational correlation of welfare use, the literature is much less settled on whether the relationship is causal (Duncan, Hill, and Hoffman 1988; McLanahan 1988; Solon, et al. 1988; Gottschalk 1990, 1992, 1996; Levine and Zimmerman 1996; Borjas and Sueyoshi 1997; Pepper 2000; Page 2004; Dahl, Kostøl, and Mogstad 2014). Instead, the parent-child link in welfare participation could simply be a spurious by-product of incomes that are correlated across generations. That is, low economic mobility across generations means that children of parents with low incomes likely have low incomes themselves in adulthood, and both generations participate in means-tested programs solely because of their shared poverty status and not welfare exposure per se. If true, then we would not expect generational welfare participation to fall after reform unless poverty among the young declined.

In this paper, we investigate the effect of welfare reform on the intergenerational transmission of welfare participation. We identify changes of welfare use from parent to child across regimes by exploiting the quasi-experimental variation provided by the 1990 s reforms to the Aid to Families with Dependent Children (AFDC) program in the United States. AFDC was established during the Great Depression and was the main cash transfer program for families with dependent children. Conditional on low income and assets, along with the presence of children under age 18, eligibility for assistance was an entitlement. Starting in 1992, states began 
implementing substantive changes to their AFDC programs with waivers from federal rules, and by 1996, 43 states had implemented some form of waiver affecting program features such as new work requirements, time limits on length of receipt, and caps on benefit generosity. These waivers culminated with passage of the Personal Responsibility and Work Opportunity Reconciliation Act of 1996, which replaced AFDC with the non-entitlement federal block grant program Temporary Assistance for Needy Families (TANF). Scores of papers have been written evaluating welfare reform (see surveys in Blank 2002; Moffitt 2003; Grogger and Karoly 2005; Ziliak 2016), but what is not known is whether it achieved a key aim of ending the transmission of welfare across generations.

To estimate the effect of welfare reform on the intergenerational transmission of welfare participation, we assemble a long panel of mother-daughter pairs over the survey period 19682013 in the Panel Study of Income Dynamics (PSID). We focus on mother-daughter pairs because over 90 percent of AFDC cases were headed by a single mother, and there has been a large secular increase since the 1960s in the fraction of first births to unmarried women in the U.S. from fewer than 1 in 10 to over 4 in 10 such that more than one third of U.S. children were exposed to welfare by age 10 (Levine and Zimmerman 2005; Cancian and Reed 2009). Our empirical framework augments a canonical transmission model whereby the welfare participation of the daughter during adulthood is regressed on the prior welfare participation of the mother with a difference-in-difference-type specification that includes a variable reflecting the implementation of welfare reform in the mother's state and the interaction of the welfarereform variable with mother's participation. Because states implemented reforms at different times starting in 1992, the variation across states over time permits us to separate out the effect of mothers' participation in the pre- and post-welfare reform periods. 
Even though welfare reform provides exogenous variation in access to program benefits across welfare eras, identifying whether there is a causal pathway from parent to child in welfare use within periods is complicated by four-potentially reinforcing—-forms of bias. First, selection bias in welfare participation across generations can arise through possible unobserved correlations in labor market productivity between the parent and child, perhaps because of latent shared cognitive or noncognitive skills, or shared tastes for welfare relative to work (Solon, et al. 1988; Gottschalk 1992, 1996; Pepper 2000). The second threat to identification comes from potential misclassification bias in survey responses (Bollinger and David 1997, 2001; Hausman, Abrevaya, and Scott-Morton 1998; Kreider, et al. 2012; Meyer and Mittag 2014). In transfer programs, this nonclassical measurement error mostly comes in the form of "false negatives" when the respondent states they did not participate in a program when in fact they did. Meyer, Mok, and Sullivan (2015a,b) document a trend increase in misreporting across all major household surveys in the U.S., including the PSID. Third, so-called life-cycle bias and the 'windows problem' may affect intergenerational estimates of economic status because we generally only observe snapshots of a parent and child and not their full life cycles (Wolfe, et al. 1996; Page 2004; Haider and Solon 2006; Nybom and Stuhler 2016). In the welfare context, this form of bias may exacerbate or attenuate intergenerational transmission estimates depending on whether the window of parent-child observations is dominated by families in the midst of longterm welfare spells. Fourth, there could be bias in the transmission estimates if the daughter moves across states as an endogenous response to the generosity of the state's welfare system (Levine and Zimmerman 1999; Gelbach 2004; McKinnish 2007; Kennan and Walker 2010). We address potential endogenous selection into welfare by instrumenting for mother's welfare use. Because selection is likely to be time-varying, we instrument mother's welfare 
participation with the state maximum AFDC/TANF benefit guarantee and the maximum federal and state Earned Income Tax Credit (EITC) when daughters are ages 12 to 18 . These instruments are constructed during a daughter's critical ages of exposure to her mother's potential welfare, which is generally well before she faces a participation decision as an adult. The mother's welfare participation decision is assumed to respond positively to greater state-level AFDC/TANF benefit standards, whereas EITC benefits may offer a substitute for AFDC/TANF assistance. Fundamentally, these aggregated measures of state-level policies identify the portion of a mother's participation decision that are related to her welfare status separately from conditions related to her poverty status, and consequently, her daughter's future poverty status.

Next, we address the implications of misclassified welfare participation, which may occur in both the dependent variable for daughters as well as the independent variable for mothers. Instruments for mother's participation will partially address misclassification in the right-hand-side variable, and we use a relatively long time history to determine whether the mother ever participated on welfare in the past, which also should attenuate measurement error compared to a contemporaneous measure. We address misclassification bias in the dependent variable by parametric methods using "extra-sample" information based on PSID reporting rates estimated in Meyer, et al. (2015b).

We attempt to mitigate the influence of the life-cycle windows problem by using the relatively long time series for each mother-daughter pair now available in the PSID. We require the mother and daughter to live together at least 5 years during the critical exposure period of ages 12-18, and to observe the daughter for at least five years after she forms her own family unit. On average, we observe mothers and daughters co-residing for 14 years, and daughters for nearly 25 years as head of their own family, and thus we observe the full welfare lifecycle for 
many mother-daughter pairs. As a sensitivity check, we also estimate a variant of the model with the Lee and Solon (2009) age-adjustment in order to re-center the data at a common point in the mothers' and daughters' life cycles. Lastly, for the issue of cross-state mobility, we examine the sensitivity of estimates to possible endogenous migration by examining various subsamples of non-movers.

Our estimates show that there is strong evidence for a causal transmission of AFDC/TANF participation from mother to daughter, and it is economically sizable, on the order of 25 to 35 percentage points. However, welfare reform significantly attenuated the level of transmission pathway by at least 50 percent, or at least 30 percent over the baseline probability. The transmission pathway is stronger for mothers with longer-term dependence as well as for black families, and the effects of welfare reform seem more pronounced in states with lessaggressive reforms possibly indicating that TANF evened the field in terms of state welfare stringency. Estimates of the reform effect are robust across a variety of specifications, including the length of mother-daughter observation window, the age of welfare exposure by the daughter when living at home, life-cycle age adjustments, and misclassification error. However, when we broaden the definition of welfare received by the daughter to also include participation in food and disability assistance programs, then the transmission from mother to daughter after welfare reform does not decrease, likely owing to the persistence in intergenerational poverty status.

\section{Welfare Reform and Intergenerational Transmission}

"Welfare" in the U.S. through the 1980s was largely defined by the AFDC program, which was established as part of the Social Security Act of 1935 to assist low-income families with children under age 18. Initially, assistance was restricted to the children of destitute widows and widowers, and then later was expanded to cover the guardian of the child, and eventually a 
second parent if present in the household. In well over 90 percent of the cases, the family was headed by a single mother. Eligibility for assistance (conditional on the presence of a dependent child under age 18) was determined by an income test, a liquid asset test, and a vehicle asset test. The federal government set rules on what counted as income or an asset, and also established limits on the dollar value of those resources. States did have authority to set maximum benefit levels (which increase with family size) and need standards used in assigning income eligibility. The program was an entitlement funded by a federal-state matching grant based on state percapita income, with the federal government picking up over 60 percent of expenditure on average (Ziliak 2016).

Beginning in the 1960s, states could apply for waivers from federal rules to experiment with program features, but with few exceptions, they did not utilize this flexibility, and when they did, it was typically for small pilot programs. This changed in the last half of the President George H.W. Bush administration when several states filed waiver applications, and then accelerated under President Clinton, who had pledged to "end welfare as we know it" as part of his 1992 campaign. By 1996, 43 states had waivers approved by the Department of Health and Human Services (Grogger and Karoly 2005). The waivers were far reaching, and included both strengthening and expanding of pre-existing policies (e.g. work requirements and sanctions on benefits for failing to work or participate in a training program introduced as part of the Family Support Act of 1988), as well as new policies aimed at family responsibility (e.g. caps on the generosity of benefits by family size and time limits on benefit receipt). Some of the new policies actually expanded eligibility, such as higher asset limits and earnings disregards for benefit determination, but the majority were designed to restrict program access. Time-limit waivers in particular were introduced to break long-term spells on AFDC, and in turn to reduce 
exposure of children to parental use of welfare.

The state-level waivers were codified into federal law with passage of the Personal Responsibility and Work Opportunity Reconciliation Act (PRWORA) in August of 1996. PRWORA replaced AFDC with a new program called Temporary Assistance for Needy Families (TANF), which is not an entitlement. The new law established federal maximum guidelines regarding funding, work requirements, and time limits, but otherwise devolved much more program design authority to the states. For example, the federal lifetime time limit for benefits for an adult is five years, but nearly half the states opted to impose shorter limits. Nineteen states now require some form of mandatory job search at the point of benefit application, and in fourteen of those states the sanction for noncompliance is to deny the application. Seventeen states have opted to impose a family cap on benefit generosity, and thirty-two states introduced "diversion payments" that steer eligible applicants away from the official caseload and instead toward a lump-sum payment, typically valued at three months of the maximum benefit for a given family size (Ziliak 2016).

[Figure 1 here]

Figure 1 depicts trends in the number of persons on AFDC/TANF, spanning the AFDC era (1960-1991), the major waiver period (1992-1996 shaded in gray), and the TANF era (from 1997 onward). Participation accelerated throughout the 1960s from about 3 million persons in 1960 to 10 million a decade later. The level of recipients remained fairly constant for nearly two decades, and then increased by approximately 30 percent from 1989 to 1994. By 2012, however, the number of recipients had plummeted 67 percent to levels roughly the same as five decades earlier. Numerous studies demonstrated that while the economy accounted for more of the decline in welfare in the mid 1990s, welfare waivers also reduced participation, especially in 
those states adopting more stringent responsibility and time limit policies (Council of Economic Advisers 1997; Ziliak et al. 2000; Blank 2001; Grogger 2003). For those few studies that examined caseload decline after passage of PRWORA, greater weight was given to policy reforms in accounting for the decline in participation compared to the waiver era, though the macroeconomy was still the driving force (Grogger and Karoly 2005). The declining participation stemmed more from reduced entry onto welfare than from increased exits (Grogger, Haider, and Klerman 2003; Haider and Klerman 2005; Frogner, Moffitt, and Ribar 2009).

Families that received AFDC were categorically eligible for food assistance from the Food Stamp Program, which started in 1964 but took nearly a decade to roll out nationwide (and was renamed Supplemental Nutrition Assistance Program (SNAP) in 2008). Receipt of AFDC was not necessary for eligibility for food stamps, but it was sufficient, and typically about 80 to 90 percent of AFDC recipients took up both (Green Book 1994). This categorical eligibility remained after the introduction of TANF. While any given individual on AFDC could not simultaneously receive assistance from the disability program Supplemental Security Income (SSI), which began in 1972, it was possible for families to combine benefits with some on AFDC and some on SSI (and still also qualify for food stamps). These provisions remain after welfare reform.

Figure 1 also presents trends in the number of recipients on food stamps and SSI. There was a marked drop in food stamp participation in the immediate aftermath of welfare reform, followed by a huge expansion in the subsequent decade. These swings have been attributed to changes in the macroeconomy, welfare and food stamp policies, and in program take-up rates among those eligible (Ganong and Leibman 2013; Ziliak 2015). There has also been growth in SSI, especially after 1990 when the Supreme Court's Zebley Decision expanded eligibility for 
children (Kubik 1999), and again after welfare reform where there is some evidence that states systematically facilitated the applications of former AFDC recipients for SSI program benefits (Schmidt and Sevak 2004). The implication then is that even if welfare reform succeeded in breaking the generational cycle on AFDC/TANF, it is not clear a priori that it reduced dependence more broadly when additional safety net programs are considered.

[Figure 2 here]

As motivating evidence for the role of welfare reform on the intergenerational transmission of dependence, Figure 2 presents the correlation between mother's and daughter's welfare participation for rolling cohorts of daughters over time based on the PSID. No attempt is made here to separate out cause and effect, only correlations over time in order to illustrate the trend and to anchor our estimates to those in the prior literature as summarized in Page (2004). ${ }^{1}$ Figure 2 shows that the intergenerational correlation in welfare increased throughout the two decades leading up to the passage of welfare reform, and indeed did not peak until 1998 when the correlation of 0.40 was more than double that of the late 1970s. The correlation between mothers' and daughters' AFDC/TANF use then fell precipitously afterwards to levels comparable to those in the early 1980s. However, if we expand the definition of daughter's welfare to include food stamps or SSI (mother's welfare remains defined by AFDC/TANF use), then we see a very different pattern. The intergenerational correlation is relatively constant after

\footnotetext{
${ }^{1}$ Specifically, across rolling cohorts of mother-daughter pairs in each year we estimate $W_{i t}^{d}=\alpha_{t}+\delta_{t} W_{i t}^{m}+\epsilon_{i t}^{d}$ where $W_{i t}^{d}$ and $W_{i t}^{m}$ are the daughter's and mother's welfare indicators, respectively, $\delta_{t}$ is the year-specific intergenerational correlation in welfare use, and $\epsilon_{i t}^{d}$ is the error term. In order to make our estimates comparable to Page (2004), we use daughter's PSID core longitudinal weights at age 25 in estimation, and we temporarily define our sample and measures of welfare participation for the purposes of Figure 2. For each year $t$, our sample consists of daughters ages 27-42 years old who are the heads of their family unit and the dependent variable is an indicator for any welfare use by the daughter between ages 14 and 27. The independent variable is an indicator for mother's welfare use prior to the daughter's matriculation to family headship.
} 
welfare reform. The descriptive evidence thus points to the possibility that welfare reform succeeded in reducing the transmission of AFDC/TANF use across generations, but dependence more broadly defined has not changed.

To identify the intergenerational dependence parameter, one naturally has to separate the poverty trap from the welfare trap. The correlations presented in Figure 2 can simply reflect persistence in poverty status, and thus, the evidence does not imply that welfare generated dependence on government assistance transmitted from mother to daughter. The literature, however, has elaborated on potential mechanisms beyond the poverty mechanism (see, e.g., Moffitt 1983; Duncan et al. 1988; Antel 1992; Durlauf and Shaorshadze 2014). First, a mother's participation might lower her daughter's stigma associated with welfare as well as other costs of participation. A child on welfare can observe and learn how the program 'works', while her mother does not incorporate potential future costs on her daughter in her utility-maximizing behavior. Secondly, contrasting the idea that welfare offers mothers additional resources in times of need, participation in government assistance affects job market opportunities for mothers, and consequently, can increase dependence for daughters through several factors such as labor force attachment and social capital, for example. Essentially, the reform targeted these plausible intertemporal mechanisms. Therefore, a framework for identifying the intergenerational transmission of dependence needs to move beyond the correlations presented in Figure 2 by considering that the reform could affect daughters' participation decisions. We discuss further details on identification in the next section.

\section{Estimating Intergenerational Transmission Pre- and Post-Reform}

Contemporary empirical studies on intergenerational socioeconomic outcomes trace their intellectual foundation to the work of Becker and Tomes $(1979,1986)$, who provide a structural 
framework of dynastic family decision making. The corresponding canonical statistical model involves regressing the outcome of interest of the child on the corresponding outcome of the parent, whether it is earnings, education, health, income, wealth, or in our case, welfare participation (see surveys in Solon 1999; Black and Devereux 2011). The prima facie evidence in Figure 2 suggests a structural break in (AFDC) welfare participation starting during the reform era. Introducing welfare reform implies a straightforward modification to the canonical model of the intergenerational transmission of welfare before and after reform as

$$
W_{i s t}^{d}=\alpha+\beta^{\prime} \boldsymbol{x}_{i s t}^{d}+\delta W_{i s, \forall j<t}^{m}+\gamma R_{s t}^{m}+\theta R_{s t}^{m} W_{i s, \forall j<t}^{m}+\varepsilon_{i s t}^{d},
$$

where $W_{i s t}^{d}$ is an indicator variable that takes a value of 1 if the daughter $(d)$ in family $i$ residing in state $s$ at time period $t$ participates in welfare and 0 otherwise; $W_{i s, \forall j<t}^{m}$ takes a value of 1 if the mother $(m)$ ever participates in welfare in any prior period $j=1, \ldots, t-1$ and 0 otherwise; $\boldsymbol{x}_{i s t}^{d}$ is a vector of observed demographic characteristics of the daughter; $R_{s t}^{m}$ is an indicator variable that takes a value of 1 when the state of residence of the mother implements welfare reform and 0 otherwise; and, $\varepsilon_{i s t}^{d}$ is an unobserved error term. ${ }^{2}$ In this specification, once the mother participates, the $W_{i s, \forall j<t}^{m}$ variable remains "on" for each subsequent observation. The use of ever on welfare for the mother instead of contemporaneous participation serves two purposes: first, it implies that once the mother participates in welfare it cannot be "unlearned" by the daughter; and second, the ever-on measure captures a longer window and thus attenuates potential measurement error. The baseline models define welfare of the daughter and mother as participation in AFDC/TANF, but we also estimate models of multiple program participation on

\footnotetext{
${ }^{2}$ While the notation implies that the daughter and mother share the same state $s$, this constraint is nonbinding in practice where welfare reform implementation and state-level instruments correspond to the mother's state of residence. We test the robustness of the estimates to possible cross-state mobility below.
} 
AFDC/TANF, food stamps/SNAP, and SSI. ${ }^{3}$ In addition, we also explore heterogeneity in the transmission mechanisms by age of the daughter when exposed to the mother's welfare use, as well as the length of exposure to the mother's welfare use.

In the conditional mean model associated with equation (1), $\delta$ is the intergenerational correlation of welfare participation, and $\delta+\theta$ is the correlation after welfare reform. This specification is akin to a difference-in-difference model whereby we exploit the quasiexperimental variation induced by the fact that different states adopted welfare reform at different times starting in the early 1990s. ${ }^{4}$ That is, the indicator $R_{s t}^{m}$ "turns on" when the state $s$ implements a waiver and remains on thereafter. By adopting this functional form, we implicitly assume that the TANF program implemented after PRWORA is a continuation of the reforms begun during the waiver period for those states that were early adopters of reform. This has been a standard assumption in the welfare reform literature, though in some cases researchers allow a trend break between the waiver era and TANF era (Blank 2002). If welfare reform succeeded in reducing the transmission across generations, then we expect that $\theta<0$.

A ubiquitous challenge across the intergenerational transmission literature has been establishing a causal pathway from parent to child, i.e. separating out the poverty trap from the welfare trap, because the conditional mean assumption for consistency of least squares that $E\left[\varepsilon_{i s t}^{d} \mid W_{i s, \forall j<t}^{m}, \bullet\right]=0$ is generally violated. In all the models estimated in this paper, the error term of equation (1) is specified as $\varepsilon_{i s t}^{d}=\mu_{s}^{d}+\rho_{t}^{d}+v_{i s t}^{d}$, where $\mu_{s}^{d}$ is a time-invariant state fixed effect, and $\rho_{t}^{d}$ is a common year effect. The state effect controls for permanent differences

\footnotetext{
${ }^{3}$ The prior literature generally only provided estimates of AFDC with General Assistance (e.g. Gottschalk 1996), or of combined AFDC/GA/Food Stamps/SSI in main results with some discussion of estimates restricted to AFDC/GA (e.g. Solon, et al. 1988; Page 2004).

${ }^{4}$ Ziliak, et al. (2000) show that a state's decision to apply for an AFDC waiver was not an endogenous response to caseload size, which supports the use of the waiver reform period as identifying variation for welfare participation.
} 
in states such as natural endowments that affect economic opportunities, while the time effect controls for macroeconomic and policy changes affecting all daughters the same in a given year. While the state and year effects are likely to control for some forms of endogeneity, it is still possible that the remaining time-varying error term $v_{i s t}^{d}$ can be correlated with the independent variables from endogenous selection, measurement error, life cycle factors, and geographic mobility. We discuss each of these threats to identification and how we propose to address them.

\section{A. Selection Bias}

The conditional mean independence assumption for consistent causal estimates of the intergenerational parameters $\delta$ and $\theta$ will break down if there are unobserved characteristics common to the mother and daughter that affect the decision to participate. That is, if we backdate equation (1) by a generation considering a year, say $-t$, and write a model of the mother's participation as a function of her demographics $\left(\boldsymbol{x}_{i s,-t}^{m}\right)$ and the welfare choice of her mother (i.e. the daughter's grandmother, $W_{i s, \forall k<-t}^{g}$ ), then shared tastes for work and welfare within families would imply that $E\left[v_{i s t}^{d} v_{i s,-t}^{m} \mid \boldsymbol{x}_{i s t}^{d}, W_{i s, \forall j<t}^{m}, R_{s t}^{m}, x_{i s,-t}^{m}, W_{i s, \forall k<-t}^{g}\right] \neq 0$. The quasi-experimental design of using cross-state variation over time in adoption of welfare reform allows us to separate the pre- versus post-reform eras, but within the AFDC and TANF eras there still remains a possible convolution of state dependence (welfare trap) and unobserved heterogeneity (poverty trap).

There have been several efforts over the years to control for endogenous selection in intergenerational welfare participation. In an early study, Solon, et al. (1988) used pairs of sisters in order to control for shared family background (i.e. family fixed effects) in identifying the effect of parental welfare participation. Antel (1992) adopted Heckman's (1978) dummy 
endogenous variable model within the context of a two-limit tobit specification. He included exclusion restrictions in the mother's reduced form equation such as the state's AFDC benefit guarantee and local labor market conditions as proxied by net migration flows. In lieu of exclusion restrictions, Gottschalk (1996) addressed unobserved heterogeneity by modeling the event histories of daughter's and mother's welfare usage in order to identify causal effects relative to a mother's past participation. Levine and Zimmerman (1996) used mother's background as additional control variates, as well as state (e.g. welfare generosity) and local (e.g. county unemployment rate) variables as instruments for mother's welfare participation. Dahl, et al. (2014), who examined disability insurance in Norway, used the random assignment of appellate-court judges as an instrumental variable to identify parent's disability participation on child's disability insurance claims. Pepper (2000) eschewed point identification methods of the latter authors in favor of nonparametric bounding techniques to control for selection as proposed by Manski (1995). Antel, Gottschalk, Pepper, and Dahl, et al. all conclude that parent's participation in welfare is causal for the child and not spurious, while Solon, et al. and Levine and Zimmerman provide evidence more in favor of spurious poverty traps.

Our approach to address possible endogenous selection within welfare regimes is to extend the prior point identification literature by exploiting the comparatively long time histories now available in the PSID and estimate equation (1) via instrumental variables. Specifically, we instrument for mother's previous welfare participation using the policy parameters defined by the state maximum AFDC/TANF benefit guarantee and the combined Federal and state maximum EITC. Each of these instruments vary across states, time, and family size - the maximum AFDC/TANF guarantee is set by state legislatures, while the maximum Federal EITC is set by the U.S. Congress to vary by the number of qualifying children in the family and the state 
portion is set by state legislatures as a fixed percentage of the Federal credit. Both of the variables speak to the prospect of the welfare trap, but in opposite directions. A higher maximum AFDC/TANF benefit guarantee means that all else equal welfare is more attractive to the mother, while a higher maximum EITC means that work is more attractive than welfare since EITC eligibility is work conditioned. To ensure that the policy instruments are most salient to the mother's welfare choice, we restrict the time period of the instruments by aggregating over values that are applicable to the mother when her daughter is in the critical exposure ages of 1218 years old and not an adult living independently. These welfare policies while the daughter is young should have no effect on her subsequent welfare decisions in adulthood except via the welfare choice of her mother (Antel 1992; Moffitt 1992; Levine and Zimmerman 1996). We describe these instruments in more detail below in the data section, and test both the first-stage strength and the validity of overidentifying restrictions in the results section. We also test the robustness to different combinations of instruments as well as to additional instruments such as the state unemployment rates.

\section{B. Misclassification Bias}

Misreporting of welfare is present both at the extensive participation margin and the intensive dollar-reporting margin, it pervades all social surveys, and has gotten worse over time (Meyer, et al. 2015a,b). In the case of welfare participation, misreports can be in the form of "false negatives"- the respondent states they do not receive assistance when in fact they doand "false positives" - the respondent states they receive assistance when in fact they do not. Based on validation studies of the Food Stamp Program and TANF, most misclassifications are false negatives (Bollinger and David 1997, 2001; Meyer, Goerge, and Mittag 2014; Meyer and 
Mittag 2014, 2015). ${ }^{5}$ The reasons for the increase in misreporting are generally unknown, but this trend may in part be a result of the increasing importance of in-kind transfers in the TANF program, which are generally more difficult for the respondent to place a monetary value. Remedies for classification bias are not straightforward in the context of dichotomous variables. A standard approach for continuous variables in the intergenerational income literature with classical measurement error is to take 3- or 5-year averages of parent's (and possibly child's) income (Solon 1992, 1999; Mazumder 2005). While such averages are likely to improve things in dichotomous participation models, this is not ensured as the errors have been found to vary systematically with characteristics and are nonclassical. Some have proposed parametric or semiparametric adjustments to the likelihood function to incorporate misclassification (Bollinger and David 1997, 2001, 2005; Hausman et al. 1998; Meyer and Mittag 2014), while others have proposed partial-identification nonparametric bounding techniques (Bollinger 1996; Black, Berger, and Scott 2000; Molinari 2008; Kreider, et al. 2012; Kreider, Pepper, and Roy 2016). These solutions have been proposed for cross-sectional data either for measurement error in the dichotomous dependent variable, or the independent variable, though we have potentially mismeasured dichotomous variables on both the left- and right-hand sides of the equation. We consider several potential remedies for misclassification bias. First, evidence in Bollinger and David (2005) showed that respondents have a latent propensity to report or not report, and that cooperation increases with length of panel participation. As we describe in the Data section, since we follow mothers for at least 14 years on average and daughters for 25 years, correct reporting should be more prevalent than in a sample with short observation

\footnotetext{
${ }^{5}$ When false positives do occur, the issue is often misreporting the correct source of actual transfer income or mistaking the timing of receipt, thus aggregate measures of welfare participation over time or across survey questions should diminish the relevance of this error type.
} 
windows. Second, for right-hand-side mismeasurement of mother's participation, again recall that we measure if the mother ever participates, which is likely to be less noisy than contemporaneous participation. ${ }^{6}$ Moreover, the instrumental variables discussed in the prior section on selection bias are also likely to improve matters for misreports of mother's participation. Third, for left-hand-side classification error, we consider parametric biascorrections along the lines proposed in Bollinger and David (1997, 2001) and Hausman, et al. (1998). Specifically, we follow Hausman et al. (1998) and assume that misreporting is independent of model covariates and constant across individuals, which implies that the partial effect of mother's participation on daughter's participation in equation (1) from observed data is proportional to the true partial effects,

$$
\begin{aligned}
\mathrm{P}\left(W_{i s t}^{d}=1 \mid W_{i s, \forall j<t}^{m}=1, \bullet\right)-\mathrm{P}\left(W_{i s t}^{d}=1 \mid W_{i s, \forall j<t}^{m}=0, \bullet\right) & = \\
& \left(1-\tau_{0 t}-\tau_{1 t}\right)\left(\delta+\theta R_{s t}^{m}\right),
\end{aligned}
$$

where $\cdot$ represents other controls, $\tau_{0 t}$ is the false positive reporting rate at time $t$, and $\tau_{1 t}$ is the false negative reporting rate at time $t$. To implement this correction, we set the false positive rate to 0 , and for the linear probability models rescale all the right-hand-side variables in equation (1) by $\left(1-\hat{\tau}_{1 t}\right)$, which is based on estimates of AFDC/TANF reporting rates in the PSID by Meyer, Mok, and Sullivan (2015b) as depicted in Appendix Table A1. Appendix A offers additional details on the two-stage approach to estimate the parameter of interest in equation (2).

\section{Life-Cycle Bias}

A data constraint facing most intergenerational research is that full life cycles of

\footnotetext{
${ }^{6}$ For further support that the mother's indicator for any prior welfare participation is measured more accurately, Appendix A demonstrates how the probability of ever misreporting tends to zero as the number of mother observations increases.
} 
daughters and mothers are generally not available. This leads to two related forms of bias, potentially reinforcing. One form of bias results from the fact that mothers and daughters are typically observed at different points of their life cycles. In the intergenerational income mobility literature, this has come to be known as life-cycle bias (Jenkins 1987; Haider and Solon 2006; Grawe 2006; Lee and Solon 2009; Nybom and Stuhler 2016). The issue with income is that daughters tend to be observed when young and incomes low (but rising), and mothers at middle age when incomes are high (and stable or perhaps falling). This systematic deviation of current income from lifetime income is a form of nonclassical measurement error and tends to attenuate the intergenerational correlation of incomes. In the welfare context, participation tends to be high when young, both because incomes are low and odds of the presence of young children high, and participation is low when older (for the opposite reason of the young), again leading to attenuation in the intergenerational correlation.

A related measurement issue, frequently referred to as the "windows problem" in the welfare literature (Gottschalk 1992, 1996; Wolfe, et al. 1996; Page 2004), occurs when the length of observation is too short for either, or perhaps both, generations. The windows problem is a form of measurement error in the sense that limited observations of an individual's welfare participation is an underreporting issue when complete histories are not available. Short windows could lead to underestimation of parameters if true participation is omitted, yet it could also lead to overestimation if long-term spells are overrepresented in the short window and long-term exposure matters more for transmitting dependency.

In the income mobility literature, Lee and Solon (2009) propose ameliorating the lifecycle bias by including controls for parent's age, normalized child's age, and interactions between child's normalized age and parent's income. The normalized child's age is measured as 
the deviation around age 40, which is the point in the life cycle when annual income serves as a reasonable proxy for lifetime income. ${ }^{7}$ The window problem is then addressed by taking threeor five-year averages of parent's income (Solon 1992; Zimmerman 1992; Mazumder 2005). Page (2004) experimented with various window lengths and found that previous estimates of welfare transmission were downward biased because the daughters were observed for shorter windows earlier in their life cycle, and in particular, that length of daughter's window mattered more than length of mother's window (but both mattered).

Our primary solution to the life-cycle bias and window problem is to utilize the much longer time series now available in the PSID compared to prior studies, though we also introduce life-cycle adjustments as in Lee and Solon (2009). For each mother-daughter pair, we observe the daughter as head/spouse of her own family unit for 25 years on average and for as long as 38 years. In addition, we observe the mother and daughter co-residing for 14 years on average with at least 5 years during the daughter's ages 12-18 when the potential for welfare learning is heightened. Thus, we come much closer to approximating the life cycle of welfare participation, especially given the requirement of dependent children under age 18 and the fact that fertility of low-income mothers tends to peak in their early to mid 20s (Lopoo 2007). However, we also present estimates that incorporate the Lee and Solon (2009) age adjustment, along with alternative observation windows that differentiate critical periods of welfare exposure. Because fertility rates among low-income women peak in their mid 20s, we detrend around daughter's age of 25 .

\footnotetext{
${ }^{7}$ Nybom and Stuhler (2016) continue to find window bias for intergenerational income estimates, even after making the Lee and Solon adjustment. Gottschalk (1996) addresses the life-cycle problem by including a long event history of mother's AFDC participation, but using a 6-year observation window for daughters.
} 


\section{Cross-State Mobility}

The power and exogeneity of the instrument variables hinge on the degree to which welfare policies determine participation, and on the extent to which families have no control over welfare policy, especially via endogenous migration. Numerous studies demonstrated that even though the economy accounted for more of the decline in welfare in the mid 1990s, welfare waivers also reduced participation, especially in those states adopting more stringent responsibility and time limit policies (Council of Economic Advisers 1997; Ziliak et al. 2000; Blank 2001; Grogger 2003). Moreover, others found that declining participation stemmed more from declining entry onto welfare, and not exit (Grogger, et al. 2003; Grogger and Karoly 2005; Haider and Klerman 2005; Frogner, et al. 2009; Ziliak 2016). This suggests that initial exposures to welfare fell in response to the policy reforms. On the other hand, the evidence on whether there is endogenous internal migration in response to welfare generosity in the U.S. is mixed (Levine and Zimmerman 1999; Gelbach 2004; McKinnish 2007; Kennan and Walker 2010), yet when effects are found, they are very small in magnitude. Also, Ziliak, et al. (2000) show that states' decisions to adopt waivers were not an endogenous response to the growing welfare caseload in the early 1990s. Both of these suggest that state-level welfare policies like the maximum guarantee are exogenous to an individual's welfare choice. We examine the robustness of the estimated intergenerational transmission parameter considering several sample restrictions to non-movers, such as daughters residing in their birth state during adulthood and daughters who never move states during adulthood.

\section{Data}

The data come from the Panel Study of Income Dynamics (PSID), which was begun in 
1968 as a survey of 4,800 American families. The survey has followed the children and grandchildren of original sample parents as they split off to form their own households so that today there are over 10,000 PSID families and 24,000 individuals. As the longest continuously running longitudinal survey, the PSID is ideally suited for the study of intergenerational transmission, and has been found to be robust over time to changes in sample composition (Fitzgerald, Gottschalk, and Moffitt 1998; Fitzgerald 2011). The original sample drew about 60 percent of the families from the nationally representative Survey Research Center (SRC) subsample, and the other 40 percent from an oversample of low-income and minority families as part of the Survey of Economic Opportunity (SEO) subsample. We focus on linked motherdaughter pairs over the entire life of the PSID survey years from 1968-2013, and in order to ensure adequate sample sizes we include observations from both the SRC and SEO subsamples.

The oversample of low-income families in the PSID allows for more precise estimation of welfare participation, yet this unrepresentative sample will yield biased causal estimates if, after conditioning on control variables, the selection probability remains endogenous to daughter's welfare participation, or if there exist heterogeneous transmission effects relative to the oversampled population (see Solon, Haider, and Wooldridge 2015). ${ }^{8}$ Some examples in the literature have addressed endogenous sampling directly by controlling on observed characteristics (Corcoran, et al. 1992; Pepper 2000), or by restricting the estimation sample to the SRC only (Moffitt and Gottschalk 2002; Lee and Solon 2009). Other examples have used weights for estimators that are based on frequency counts (Solon, et al. 1988; Page 2004), as a sensitivity check (Solon 1992), or in the main estimation (Hoynes and Schanzenbach 2012). A primary concern for our estimates is the potential heterogeneity of welfare participation

\footnotetext{
${ }^{8}$ See PSID documentation for background on survey selection procedures and sample weight construction. For detailed issues relate to the Survey of Economic Opportunity, see Brown (1996).
} 
transmission by race coupled with overrepresented low-income, minority families, and our model maintains a fairly parsimonious structure that may not adequately account for this source of bias. Therefore, in all of our estimation results, we provide weighted estimates with the unweighted versions in brackets below.

In an effort to address the issues of selection bias, life cycle bias, and the windows problem, our baseline sample consists of mother-daughter pairs that are observed for at least five years while the daughter is living in the same household during the critical exposure period spanning the ages of 12-18, and that the daughter is observed at least five years as the head of her own family unit. Selecting adolescence and teenage years as the observation window for childhood exposure pervades the welfare transmission literature (Solon, et al. 1988; Duncan and Yeung 1995; Gottschalk 1996; Pepper 2000; Page 2004). Part of this stems from data needs; that is, if we require observing early childhood as well as enough years in adulthood, then we will impose greater demands on the data in terms of length of time in the panel and in turn end up with fewer mother-daughter observations. The other reason for focusing on adolescent and teenage years is that cognitive, emotional, and physiological development are sufficiently advanced for the potential of "welfare learning" from the parent. However, it remains an open question in the literature which stage of childhood development is most important for the potential of welfare learning. Research shows that economic deprivation in early childhood has more deleterious effects in terms of achievement and health in early adulthood than does similar deprivation during adolescence (Duncan, et al. 1998; Duncan and Brooks-Gunn 2000; ZiolGuest, et al. 2012; Elango, et al. 2016). But this research has not separated out the independent role of welfare in this process. As such, we follow convention and focus on the five years observed during the ages 12-18 as a key period of welfare exposure for our baseline models, and 
then explore how the estimates change as the age of exposure changes.

A daughter is considered an adult at first childbirth or when establishing a new family unit if she is at least age 14, though she may continue to live at home as a subfamily. This yields a baseline sample of 2,961 mother-daughter pairs spanning 56,067 observation years of the daughter as an adult. On average, we observe mothers and daughters co-residing for 14 years in total and for 6.3 years during the critical ages of 12-18, and we observe daughters as adults for 25 years. In the results section, we report estimates from specifications that both loosen and tighten the observation windows for both mothers and daughters, and also examine the length of exposure.

[Table 1 here]

Table 1 contains the key variables from the baseline sample used in estimation of equation (1), separated into the pre- and post-welfare reform eras, and weighted by the daughter's core longitudinal weight. The dependent variable takes on a value of 0 or 1 based on whether the daughter participates in welfare at any time after she has formed her own family unit. We consider two definitions of welfare, one that captures participation in AFDC/TANF or "other welfare" such as General Assistance (which we simply refer to as AFDC/TANF for succinctness), and a second which captures participation in any of AFDC/TANF, food stamps/SNAP, or SSI. ${ }^{9}$ This variable varies over time because of possible movements on and off welfare across her life course. While 4.4 percent of daughters receive AFDC/TANF as adults in an average year over the sample period, as seen in Table 1, the odds of participation are nearly

\footnotetext{
${ }^{9}$ The PSID asks about AFDC/TANF receipt of the family head, spouse, and other family members, as well as an "other welfare" category (not including SSI, food stamps, workers' compensation, housing, Social Security). This other welfare category can contain assistance from various public sources including General Assistance.
} 
70 percent lower after welfare reform, falling from 8 percent to 2.5 percent. ${ }^{10}$ On the other hand, there is much more stability over time in participation in any of the three programs, with 13.2 percent receiving AFDC/TANF, food stamps/SNAP, or SSI before reform and 11.2 percent afterwards. Almost all of the additional uptake in welfare use is from food stamps/SNAP.

The key independent variable is mother's welfare participation found in the bottom panel of Table 1, which takes a value of 1 if the mother ever participates in welfare at any time prior to a given age-year of her daughter, and 0 otherwise. Table 1 shows that about 27 percent of mothers were ever on AFDC/TANF prior to welfare reform, and 6.7 percent were ever on during the period after reform, while those figures jump to 43 and 19 percent, respectively, if the mother ever received AFDC/TANF, food stamps/SNAP, or SSI. Note that it is possible for the mother to first participate on welfare after the daughter forms her own family unit. For AFDC/TANF participation, this can occur only if the mother has children (or dependents) under age 18 remaining in the household other than the focal daughter. Learning thus can occur from direct exposure while the daughter resides in the household with her mother, or from indirect "word of mouth" once the daughter forms her own family unit. We discuss this mechanism in the results section below.

The other focal regressor in equation (1) is the indicator for welfare reform. As discussed previously, states began reforming AFDC in earnest starting in 1992, four years prior to passage of PRWORA. States had to submit requests for waivers from Federal rules to the U.S. Department of Health and Human Services, e.g., to introduce a time limit on benefits or to expand asset limits for eligibility. If the waiver was approved, then there was generally a lag

\footnotetext{
${ }^{10}$ If the percent of daughters participating in AFDC/TANF are adjusted for misclassification (by inflating sample statistics by the reporting rates shown in Appendix Table A1), then the baseline participation over the sample period would be 7.8 percent of daughters, which then falls to an adjusted 5.6 percent after welfare reform.
} 
between the time of approval and when the policy was implemented. Indeed, some approved waivers never were implemented (Grogger and Karoly 2005). We thus use the implementation date of the waiver as the date when reform is first in place, and the variable remains on for each year thereafter. For those states that did not implement waivers we use the implementation date of their TANF program. While the major AFDC waiver implementation period is defined as 1992-1996, the earliest major waivers were officially implemented in Michigan and New Jersey as of October 1992, and the latest implementation of TANF was in New York as of November 1997. In our data, the implementation of welfare reform is denoted by the earliest year in which at least 3 quarters of the year are observed after reform (either by waiver or TANF), implying that the reform variable spans $1993-1998 .{ }^{11}$ We achieve identification because of cross-state variation over time in the welfare reform indicator. As seen in Table 1, 65 percent of daughteryear observations occur after welfare reform is implemented, while for mothers it is just about 14 percent.

Table 1 also contains demographic characteristics of the daughter and mother, including age, race, number of children, and geographic mobility. Daughters are 28 years old on average before reform and 39 after reform, while mothers are 43 and 59 years old, respectively, highlighting the long observation windows we observe families compared to prior research. For the estimation sample, approximately 72 percent of daughters reside in their state of birth during adulthood. ${ }^{12}$ We use four measures of welfare generosity for our instruments: the average and maximum state-specific AFDC/TANF benefit standard for families of 2, 3, or 4 or more persons, and the average and maximum combined Federal and state EITC benefit for 0, 1, or 2 or more

\footnotetext{
${ }^{11}$ For specific dates of welfare reform waiver approval and implementation, see Crouse (1999).

${ }^{12}$ Also, statistics not shown in Table 1 indicate that 63 percent of daughters live in the same state as their mothers, while 57 percent never change states during the entire observation period.
} 
dependents. The EITC benefit is defined as $\operatorname{EITC}_{i t} *\left(1+p_{i s t}\right)$, where $E I T C_{i t}$ is the Federal credit that varies by the number of qualifying children and year and $p_{i s t}$ is the fraction of the Federal EITC that a state refunds on the state return. The Federal EITC was begun in 1975, and expanded in 1986, 1991, 1993, and 2009, while states began introducing the refundable state EITC in the late 1980s. By the mid 2000s, nearly half the states had a separate EITC, providing cross-state and family-size variation over time in the instrument. The nominal values of the maximum guarantees and credit are converted to real 2012 dollars using the personal consumption expenditure deflator. ${ }^{13}$

\section{Results}

In presenting the empirical results, we first focus on the baseline linear probability model correcting for nonrandom selection, misclassification error, life-cycle bias, and cross-state mobility in order to provide a baseline estimate of welfare transmission and the effects of welfare reform. We then explore timing of transmission by age and duration of exposure, heterogeneity by race and welfare reform aggressiveness, and transmission through multiple program participation. All models control for time-varying demographic controls of the daughter (a quadratic in her age and indicators for the number of children in her home) as well as dummy variables for state of residence and year. The standard errors are robust to heteroscedasticity and clustered at the state level given the focus on state welfare reforms.

\footnotetext{
${ }^{13}$ Source: U.S. Bureau of Economic Analysis, 2016, Personal Consumption Expenditures Excluding Food and Energy, Chain-Type Price Index [series: DPCCRG3A086NBEA], retrieved from FRED, Federal Reserve Bank of St. Louis.
} 


\section{A. Baseline Estimates}

Table 2 contains the baseline estimates of the parameters of interest in equation (1), with and without instrumental variables and corrections for misclassification of the dependent variable. The least squares estimate of the effect of mother's AFDC participation prior to welfare reform in column (1) is 0.145 for weighted estimates and 0.203 for unweighted, which is within the range of estimates among studies from that era surveyed in Page (2004). ${ }^{14}$ That correlation falls 69 percent after welfare reform to $0.044(=0.145-0.101)$. We note that the after welfare reform variable has a positive effect on daughter's participation when controlling for daughter's age and year fixed effects, suggesting that in the absence of welfare reform the trend increase in intergenerational transmission would have continued. Column (2) presents instrumental variables estimates whereby both the direct effect of mother's participation and the interaction with welfare reform are instrumented (the interaction is identified by interacting the welfare reform indicator with the four instruments of average and maximum of mother's AFDC/TANF benefit standard and federal/state EITC by family size during the critical exposure period of daughter's ages 12 to 18$).{ }^{15}$ In the IV specification, the pre- and post-reform effect sizes of mother's participation are nearly two-thirds larger compared to estimates in column (1), thus the transmission mechanism is still attenuated by 69 percent to $0.074(=0.238-0.164) .{ }^{16}$ The null hypothesis of weak instruments is rejected using the Kleibergen-Paap rank test, while the null of

\footnotetext{
${ }^{14}$ Note that this estimate is lower than a simple average of the trend estimates in Figure 2 because the samples differ. Figure 2 depicts whether the daughter is ever on welfare before age 27, while the sample used in estimating equation (1) is for any contemporaneous welfare use after forming a family unit, regardless of daughter age. Table 2 also includes state and year effects as well as daughter control variables, while the figure shows unconditional correlations.

${ }^{15}$ Given that the model is overidentified, and the error term is possibly heteroscedastic and correlated across families within states, we therefore estimate the models using generalized instrumental variables (GIV), which can be interpreted as a form of generalized method of moments (GMM) estimator.

16 The estimated welfare transmission effect after welfare reform in column (2) has a standard error of 0.025 and is statistically different from zero with a p-value of approximately 0.003 .
} 
valid overidentifying restrictions is not, suggesting our IV estimates are consistent. Further, these estimates are robust to the addition of state unemployment rates to the instrument set, shown in Appendix Table B1, and the addition of family background controls such as mother's income and education during the daughter's critical exposure ages, shown in Appendix Table B2. ${ }^{17}$

[Table 2 here]

The results indicate a clear pattern of welfare reform reducing the transmission of participation. However, the percent changes above represent changes in levels, and it has been noted from Table 1 that the levels in welfare participation rates are quite different before and after reform. If we consider percent changes in transmission as a fraction of the baseline probability, then the effect of welfare reform in column (2) would be a 45 percent reduction $(=1$ $((0.238-0.164) / 0.025) /(0.238 / 0.044))$ using baseline participation rates for the overall period and after reform taken from Table 1. As discussed by Fang and Keane (2004), it is not clear that this statistic is necessarily more informative than the change in levels, but simply provides an alternative interpretation of the point estimates.

Note that point estimates for the unweighted results shown in brackets are larger in magnitude than the weighted estimates. Without sample weights, heterogeneity introduced by the oversampling of low-income families in the SEO upwardly biases the magnitude of mother's participation effect relative to a population average effect, yet the qualitative interpretations are the same including similar percent changes after reform. The standard errors for unweighted

\footnotetext{
${ }^{17}$ Earlier drafts included state labor market conditions in the baseline instrument set. Although prior research has demonstrated the strong role the macroeconomy plays in determining participation in AFDC/TANF, it also is a key determinant of the cyclicality of poverty rates and thus may not be as effective in separating out the poverty trap from the welfare trap. We thank Anna Aizer and Lara Shore-Sheppard for making this point. Regarding controls for mother's income and education, Levine and Zimmerman (1996) note that these variables could be endogenous to the daughter's welfare choice for the same reasons that the mother's welfare participation is likely to be endogenous.
} 
estimates (not shown but available upon request) are also larger, though by much smaller proportions such that the statistical significance of results is essentially independent of weighting choice. As a further robustness check, Appendix Table B3 re-estimates the results from Table 2 for the SRC sample showing smaller magnitudes but, again, a similar qualitative story for the effects of welfare reform.

While our baseline estimates intrinsically address misclassification of the mother's welfare participation by design (longer panels of non-attriters, instrumental variables, and ever on welfare instead of contemporaneous), we do not directly address the possibility of a binary mismeasured dependent variable. Columns (3) and (4) in Table 2 show the baseline estimates with misclassification bias corrections. As expected, the estimates are larger than those with no correction in columns (1) and (2), and indeed the corrected estimates without instruments in column (3) are on par with the uncorrected IV estimates in column (2). We note that the biascorrected estimates are likely to be upper-bounds because the estimates of reporting rates from Meyer, et al. (2015b) come from annual cross sections of the PSID but our sample consists of a long panel of stayers who tend to be more accurate in reporting (Bollinger and David 2005).

\section{[Table 3 here]}

Next, we explore how the IV estimates (without and with misclassification corrections) vary once we adjust the length of observation window for mother and daughter living together during potential years of welfare exposure, which may be critical years susceptible to life-cycle bias. We argued that our estimates are less vulnerable to this form of bias because we observe the typical daughter for two and a half decades after forming her own family unit, and that we impose the requirement that mothers and daughters co-reside at least five years while the daughter is aged 12 to 18 . In Table 3, we examine the windows problem by first eliminating 
minimum restrictions on mother-daughter observations, and then extending the minimum requirement that the pairs be observed for at least ten and fifteen years, respectively. There we see that the reduction in the level of mother's transmission after welfare reform ranges between 54 percent to 77 percent, while the reduction in terms of baseline probability of participation ranges between 36 percent and 60 percent, both of which are comparable to the estimates reported in Table 2.

[Table 4 here]

Next, in Table 4 we address potential life-cycle bias by following the method suggested in Lee and Solon (2009). Specifically, we augment the model with a quartic in the average age of the mother during prior (to time $t$ ) periods of potential welfare participation, a quartic in the detrended daughter's current age, and the interactions between the quartic in daughter's detrended age and mother's participation as well as the indicator for mother's participation after welfare reform. Note that as before the interactions with mother's welfare participation are endogenous in our setting, and therefore, in the IV models of columns (2) and (4) we instrument using the detrended quartic in daughter's age times the average of mother's AFDC/TANF benefit standard and federal/state EITC by family size when the daughter was living with the mother and she was between 12 and 18 years old, and we also use these instruments interacted with reform. Comparing the OLS estimates in column (1) of Tables 2 and 4, it is clear that the age adjustments do not influence the results qualitatively (with only small quantitative differences), which implies that the longer observation panels account for life-cycle differences adequately well. Further comparisons across columns (2)-(4) remain generally consistent with our baseline story. While the percent reductions after reform are smaller, the need for age adjustment in the context of instrumental variables and misclassification correction is not well understood, which 
may merit further research.

\section{[Table 5 here]}

Our models to this point have allowed for the possibility that daughters reside in a different state than their mothers and/or have moved to another state during adulthood. If such movements are an endogenous response to the welfare climate in the state, then this could lead to biased estimates of welfare reform and the transmission across generations. As a test on our baseline sample, we consider three alternatives to our IV models in Table 2: restricting the sample of daughters to those who reside in the same state as their birth state, restricting the sample of daughters residing in the same state as their mothers, and restricting the sample of daughters to those who never move during their observed lifetime. Table 5 shows that both the direct effect of mothers' participation and the interaction with welfare reform are larger in absolute value in Table 5 compared to estimates in Table 2, yet the changes are relatively proportional such that both the percent reduction in levels and percent-over-baseline reduction of transmission after welfare reform are roughly the same. The magnitudes of estimates in Table 5 are suggestive that the mobility of daughters across state lines can "undo" some of the intergenerational transmission of welfare, although the differences from the baseline estimates are modest.

\section{B. Timing of Welfare Transmission Effects}

We next explore potential timing of welfare transmission and reform effects based on the age and duration of daughter's exposure to mothers' welfare participation. In the first set of results, we examine how the base-case IV estimates without and with misclassification corrections in Table 2 change if we restrict the daughter's potential welfare exposure to only 
periods of co-residence. Recall that in Table 2, the daughter could be exposed to her mother's welfare use at any time in the life cycle provided it was prior to the current period $t$, including those periods when the daughter no longer lived at home but had younger siblings at home that make her mother welfare-eligible. In the first two columns of Table 6, we see that the pre-reform transmission effect is modestly larger relative to the baseline in Table 2, but again, the postreform interaction changes proportionally. This implies that welfare reform had the same percent reduction of welfare transmission among those daughters exposed only during co-residence.

[Table 6 here]

In our baseline models, we require mothers and daughters to co-reside at least five years during the ages of 12-18. As discussed in the data section, this age range was selected in part from convention in the literature, but there is little prior evidence on whether "age of exposure" mattered for welfare learning. In Figure 3, we present new empirical evidence of age at critical exposure windows by using rolling five-year and ten-year windows from age 4 through age 17 . The panels are organized with weighted estimates in the top row of panels and unweighted in the bottom row, while the left column of panels shows 5-year windows and the right column 10-year windows. The figure presents IV estimates of the pre-welfare reform effect of mothers' AFDC participation and the interaction between mother's participation and reform, along with 95percent pointwise confidence intervals. Figure 3 shows that the magnitude of the direct effect of the mother's participation increases as the age of first exposure increases, suggesting that the learning effect is stronger during adolescence and teen years relative to early childhood. The definition of a critical exposure period matters more for shorter windows given that larger windows are more likely to include some critical learning period. Also, a comparison between weighted and unweighted estimates magnifies the importance of observing the critical age 
window, e.g., the absence of survey weights in panel $\mathrm{C}$ implies a higher representation of lowincome families where the magnitude differences across ages are more pronounced.

[Figure 3 here]

As a further exploration of age of exposure, columns (3)-(5) in Table 6 present panel-data fixed-effects estimates of the welfare transmission without and with instruments and misclassification corrections. Specifically, we admit error components into the model consisting of latent person-specific heterogeneity as $v_{i s t}^{d}=\lambda_{i}^{d}+u_{i s t}^{d}$, where $\lambda_{i}^{d}$ is a time-invariant daughter fixed effect and $u_{i s t}^{d}$ is an error term. We assume that the daughter fixed effect contains a component common to the daughter and the mother from shared family heritage and experiences (including health status, attitudes), as well as that which is daughter-specific such as school quality and neighborhood. Identification of the direct, pre-reform effect of mother's participation is subtler in the fixed-effects specification. Namely, transmission can only occur via "word-ofmouth" from mother to daughter after the daughter has left home to form her own family unit. This follows from our definition of mother's prior welfare use that once the variable "turns on" it remains on for the duration that they remain in the sample. If the mother joins welfare while the daughter co-resides then we cannot separate this from the fixed effect; however, if she joins after the daughter leaves because of younger children present, then verbal transmission of the program can still occur and identify the parameters of interest. ${ }^{18}$

The direct effect of mother's transmission in column (3) of Table 6 is almost half the size of the estimate from column (1) of Table 2, suggesting that a sizable fraction of the transmission

\footnotetext{
${ }^{18}$ Appendix Table B4 restricts the sample to eldest daughters only, showing that the results of Table 2 are not sensitive to which daughter is exposed to welfare. However, the misclassification-corrected IV estimate of the effect of mother's participation after reform is statistically insignificant at conventional levels.
} 
that is passed from parent to child occurs after the daughter leaves home. In fact, the total effect after welfare reform is negative $(0.079-0.128)$, suggesting that welfare reform shut down this transmission channel. However, fixed-effects methods exacerbate attenuation bias, so it is natural to find estimates lower in absolute value. ${ }^{19}$ Once we make time-varying corrections for misclassification in column (4), the mother's direct effect only drops about one tenth from the estimate in column (3) of Table 2, though the percent change after reform is larger and we cannot reject that the mother's post-reform transmission via word of mouth is equal to zero given a pvalue of 0.293 . For completeness, given that selection is likely to be time-varying, we also present IV fixed-effects estimates with misclassification corrections in column (5), but the model is not well identified as indicated by the ten-fold increase in standard errors for the mother's direct participation effect.

[Table 7 here]

A daughter's exposure to welfare and her resulting propensity for dependence will likely vary as a function of her mother's duration of participation, or otherwise stated, her intensity of treatment exposure. Gottschalk and Moffitt (1994) propose measuring welfare dependence as the total time on welfare or the total percent of income from transfers, and Pepper (2000) models daughters' welfare outcomes depending on categorical definitions of mother's duration in years. In order to allow the mother's effect to vary by duration, we separate mother's participation into two groups: duration for at most 2 years and duration for more than 2 years (the omitted category is zero welfare participation).

Table 7 shows the effects of mother's welfare participation differentiated by short- and

\footnotetext{
${ }^{19}$ For measurement error in a dichotomous independent variable in a panel setting, see Freeman (1984); the case for errors in continuous variables in panels is addressed by Griliches and Hausman (1986).
} 
long-term welfare dependence on the same dependent variable described above, that is, a daughter's extensive-margin decision to participate in a given year. As one might expect, the effect of long-term mother's participation on welfare is larger than the effect of short-term participation in all variants of the model. ${ }^{20}$ Regardless of whether we instrument or adjust for misclassification, the estimates suggest that welfare reform had a larger effect of reducing the level and percent of longer-term spells compared to shorter-term spells.

\section{Heterogeneity of Welfare Transmission Effects}

There is a vast literature on the socioeconomic differences between blacks and whites (see, for example, Smith and Welch 1989; Duncan and Hoffman 1990; Donohue and Heckman 1991), but with the notable exceptions of Gottschalk (1996) and Pepper (2000), whether or not there are racial differences in the transmission of intergenerational welfare has received less attention compared to other outcomes. The issue is salient in part because the risk of out-ofwedlock births is at least two times higher among blacks than whites, as is the risk of poverty in childhood.

[Table 8 here]

The first three columns of Table 8 present estimates for the transmission of AFDC/TANF from mother to daughter separated by blacks and whites. Specifically, we include an indicator variable for whether the daughter is black, and we interact that with both mother's participation and welfare reform (and interact all instrumental variables with the indicator for daughter's race).

\footnotetext{
${ }^{20}$ We tested for the difference between the effect of mother's participation for greater than 2 years and participation for at most 2 years and found that we reject at 10-percent significance the equality of these coefficients in columns (1) and (3), yet the IV estimates in columns (2) and (4) do not estimate the mother's direct effect precisely enough even though the economic differences are substantial. In the unweighted estimates (where low-income families are overrepresented), we reject equality for columns (1)-(3) whereas the p-value corresponding to column (4) is 0.133.
} 
As before, all models control for state and year effects, a quadratic in daughter's age, and indicators for the number of children in the daughter's family. The first two columns in the upper panel of Table 8 without and with controls for (fixed) unobserved heterogeneity, as well as the IV estimates in column (3), suggest that the direct effect of welfare transmission was much stronger among blacks than whites. Comparing OLS and fixed-effect estimates in columns (1) and (2), the proportion of transmission that might be attributed to word of mouth after the daughter leaves home is similar for black and white families. ${ }^{21}$ However, comparing OLS to IV estimates in column (3), the direct transmission effect for IV is about 2.5 times larger than OLS for black mothers while similar in magnitude for white mothers, which implies that selection has a prominent role in black-white differences. This is similar to the finding in Gottschalk (1996). ${ }^{22}$ In all three specifications, welfare reform eliminates the transmission mechanism among whites, and reduces it by at least 44 percent in levels among blacks. It is important to note that racial disparities in intergenerational mobility may be related to institutional factors that merit further research (see, e.g., Chetty et al. 2014; Corcoran and Adams 1997).

States differed dramatically in the degree of aggressiveness in implementation of welfare reform, both in the waiver era and after TANF. While there is no agreed upon measure of strictness in the literature, we follow Grogger and Karoly (2005, Table 4.2) and define strict states as those whereby all main studies surveyed agree that the sanctions policy adopted by the state during 1992-1996 was strict (there were 13 states that met this criteria). Ziliak (2007) examines five different categories of welfare reform aggressiveness and concludes that the latter

\footnotetext{
21 This evidence should be interpreted with caution. Measurement issues on the right- and left-hand-side variables can be exacerbated in panel models with fixed effects (for errors in repeat measures of independent variables, see Freeman 1984; Griliches and Hausman 1986).

${ }^{22}$ Gottschalk's (1996) evidence in favor of causation is strongest for white families, while for black families a considerable fraction of the intergenerational link is spurious.
} 
measure was the best proxy for strict policy reforms. We then include this measure of welfare reform stringency in a triple-difference framework to test whether there were differences in intergenerational transmission in those states that adopted more-strict reforms compared to states with less-strict reforms.

The last three columns of Table 8 report estimates corresponding to the effects of interest for the triple-difference model based on state reform aggressiveness. Across all three specifications, the transmission mechanisms between mother and daughter before welfare reform were qualitatively smaller in aggressive states than in non-aggressive states based on weakly negative coefficients for the interaction between mother's participation and strictness (in results not shown but available upon request). ${ }^{23}$ This suggests that there was some permanent difference among residents in states adopting strict reforms versus less strict reforms. However, after reform, this difference was attenuated, resulting in very similar percent reductions in both the levels and probability of participation, suggesting some degree of convergence in welfare climates across states after welfare reform.

\section{The Wider Safety Net}

Even if welfare reform reduced the causal transmission of AFDC/TANF participation, a relevant policy question is the extent to which welfare defined more generally is transmitted across generations. In our last set of results, we examine what effect welfare reform had on the decision to participate more broadly in the social safety net. In Table 9, we present estimates that are parallel to Table 2; namely, all models include observable daughter characteristics, state, and

\footnotetext{
${ }^{23}$ However, the effect of mother's participation interacted with aggressive welfare reform is only statistically significant in the unweighted IV model in column (6) with a p-value of 0.006 , whereas the weighted IV estimate has a p-value of 0.187 .
} 
year effects, and they are estimated without and with instruments for mother's participation and corrections for misclassification bias. In both the top and bottom panels, we define the daughter's welfare participation as receipt of any AFDC/TANF, food stamps/SNAP, or SSI. However, we differentiate the mother's definition of prior welfare use - maintaining the AFDC/TANF definition in the top panel since it is most directly affected by welfare reform, while allowing the more general case for any mother's previous participation in AFDC/TANF, food stamps/SNAP, or SSI in the bottom panel.

[Table 9 here]

The top panel in Table 9 shows that IV estimates of the direct effect of mother's AFDC/TANF participation on daughter's use of the wider safety net was not significantly different compared to daughter's use of AFDC/TANF alone (Table 2) prior to welfare reform. However, after welfare reform, there is little evidence that the transmission channel was broken, and indeed, across all specifications the transmission mechanism is stronger after reform in terms of the baseline probability of participation. Results in the bottom panel condition daughter's wider safety net participation on her mother's wider safety net history, which shows a weaker direct link than AFDC/TANF transmission and a similar pattern as above for post-reform effects in that daughters are, if anything, more likely to use the safety net defined broadly. ${ }^{24}$

[Figure 4 here]

A possible explanation for this result is that the economic status of daughters did not improve enough after welfare reform relative to their mothers for them to attain self-sufficiency.

\footnotetext{
${ }^{24}$ For misclassification-corrected estimates in Table 9 columns (3) and (4), the reporting rate $\left(1-\hat{\tau}_{1 t}\right)$ used in estimation is the maximum reporting rate for AFDC/TANF and food stamps/SNAP shown in Appendix Table A1.
} 
We explore this possibility in Figure 4 where we present trends in intergenerational correlations between mothers and daughters akin to Figure 2, but now for four measures of economic status:

(1) poverty status defined as an income-to-needs ratio less than 1, where needs is defined by the U.S. Census Bureau poverty line that varies by family size; (2) poverty status defined as an income-to-needs ratio less than 1.3 ; (3) poverty status defined as an income-to-needs ratio less than 2; and, (4) log family income. ${ }^{25}$ We present income-to-needs cutoffs of 1.3 and 2 in addition to 1 because the Federal guideline for gross income eligibility for food stamps is 130 percent of the poverty line, but after the year 2000 , states have had the option to extend eligibility and thus we also show for a threshold of 200 percent of poverty. In the two decades from the late 1970s to 1990s, the income mobility of daughters declined (i.e. the correlation was increasing), but then stabilized thereafter. This suggests that after welfare reform daughters had continued economic need for assistance from the wider safety net.

\section{Conclusion}

A focal aim of policymakers with the 1990s welfare reform was to end dependence on welfare, and based on the metric of the intergenerational transmission between mother and daughter, the evidence presented here suggests partial success toward meeting that goal. Viewed from the lens of participation in the AFDC/TANF program, we find strong evidence across a variety of specifications that address major threats to identification including selection bias, lifecycle bias, misclassification bias, and geographic mobility, that the level of transmission from mother to daughter was reduced by at least 50 percent, and by at least 30 percent over the baseline odds of participation. However, when the definition of welfare is expanded from

\footnotetext{
${ }^{25}$ Income-to-needs ratios are constructed as the mean income to mean poverty threshold for a daughter's adult life through age 27, and for the mother's years while the daughter lives at home.
} 
AFDC/TANF to also include food and disability assistance programs, the post-welfare reform transmission does not decrease. We suggest that the latter result likely stems from the fact that broader economic mobility of daughters stagnated after welfare reform.

Implicit in the discussion surrounding welfare reform was that the transmission of welfare reliance from parent to child was inherently a bad outcome. It is not obvious, however, what is the socially efficient intergenerational correlation of welfare outcomes. For example, a correlation of zero - perfect mobility with respect to welfare use - would imply that accumulating "family capital" (wealth, culture, information, and skills) does nothing to ensure the self-sufficiency of future generations. In some cases, though, there may be positive attributes to intergenerational transmission of welfare knowledge if take-up rates are low and learning the welfare system helps needy recipients (Currie 2006). Indeed, in the few years after welfare reform, take-up rates of food stamps among those eligible fell about 20 percentage points to just over 50 percent, mainly because potential recipients were not aware of their eligibility in a postreform environment that discouraged welfare more generally (Ganong and Leibman 2013; Ziliak 2015). The policy response by USDA was to grant more authority to states to design their programs to improve take up. Presumably, among those 50 percent who continued participation, some retained eligibility was because of shared information from parent to child. This suggests a need for future theoretical and empirical research on optimal transfer program design that incorporates knowledge spillovers across generations. 


\section{REFERENCES}

Antel, J.J. (1992): “The Intergenerational Transfer of Welfare Dependency: Some Statistical Evidence," Review of Economics and Statistics, 74, 467-473.

Becker, G.S., and N. Tomes (1979): “An Equilibrium Theory of the Distribution of Income and Intergenerational Mobility,” Journal of Political Economy, 87, 1153-1189.

(1986): "Human Capital and the Rise and Fall of Families," Journal of Labor Economics, 4, S1-39.

Black, D., M. Berger, and F. Scott (2000): “Bounding Parameter Estimates with Nonclassical Measurement Error,” Journal of the American Statistical Association, 95, 739-748.

Black, S.E., and P.J. Devereux (2011): “Recent Developments in Intergenerational Mobility,” In Handbook of Labor Economics, Volume 4, O. Ashenfelter and D. Card (eds.), Amsterdam: North Holland, 1487-1541.

Blank, R. (2001): “What Causes Public Assistance Caseloads to Grow?” Journal of Human Resources, 36, 85-118.

_ (2002): “Evaluating Welfare Reform in the United States,” Journal of Economic Literature, 40, 1105-1166.

Bollinger, C. (1996): "Bounding Mean Regressions When a Binary Regressor is Mismeasured," Journal of Econometrics, 73, 387-399.

Bollinger, C., and M. David (1997): "Modeling Discrete Choice with Response Error: Food Stamp Participation," Journal of the American Statistical Association, 92, 827-835. (2001): "Estimation with Response Error and Nonresponse: Food-Stamp Participation in the SIPP," Journal of Business and Economic Statistics, 19, 129-141. (2005): “I Didn't Tell, and I Won’t Tell: Dynamic Response Error in the SIPP,” Journal 
of Applied Econometrics, 20, 563-569.

Borjas, G.J., and G.T. Sueyoshi (1997): "Ethnicity and the Intergenerational Transmission of Welfare Dependency,” Working paper, National Bureau of Economic Research, Research in Labor Economics, 16: 271-295.

Brown, C. (1996): 'Notes on the 'SEO' or 'Census' Component of the PSID,” Report, Survey Research Center, Institute for Social Research, University of Michigan, Ann Arbor, MI. Cancian, M., and D. Reed (2009): "Family Structure, Childbearing, and Parental Employment: Implications for the Level and Trend in Poverty," In Changing Poverty, Changing Policies, M. Cancian and S. Danziger, (eds.), New York: Russell Sage Foundation, 92-121.

Chetty, R., N. Hendren, P. Kline, and E. Saez (2014): "Where is the Land of Opportunity? The Geography of Intergenerational Mobility in the United States," Quarterly Journal of Economics, 129, 1553-1623.

Corcoran, M., and T. Adams (1997): "Race, Sex, and the Intergenerational Transmission of Poverty," In Consequences of Growing up Poor, G. Duncan and J. Brooks-Gunn (eds.), New York: Russell Sage Foundation, 461-517.

Corcoran, M., R. Gordon, D. Laren, and G. Solon (1992): “The Association between Men's Economic Status and Their Family and Community Origins," Journal of Human Resources, 27, 575-601.

Council of Economic Advisers (1997): "Explaining the Decline in Welfare Receipt, 1993-1996," Technical report. Washington DC: Executive Office of the President.

Crouse, G. (1999): “State Implementation of Major Changes to Welfare Policies, 1992-1998," Technical document, U.S. Department of Health and Human Services. Currie, J. (2006): “The Take Up of Social Benefits," In Public Policy and the Income Distribution, 
A. Auerbach, D. Card, and J.M. Quigley (eds.), New York: Russell Sage, 80-148.

Dahl, G.B., A.R. Kostøl, and M. Mogstad (2014): “Family Welfare Cultures,” Quarterly Journal of Economics, 129, 1711-1752.

DeParle, J. (2004): American Dream: Three Women, Ten Kids, and a Nation's Drive to End Welfare. New York: Penguin Books.

Donohue, J.J., and J.J. Heckman (1991): “Continuous Versus Episodic Change: The Impact of Civil Rights Policy on the Economic Status of Blacks," Journal of Economic Literature, 29, 1603-1643.

Duncan, G.J., and J. Brooks-Gunn (2000): “Family Poverty, Welfare Reform, and Child Development," Child Development, 71, 188-196.

Duncan, G.J., M.S. Hill, and S.D. Hoffman (1988): "Welfare Dependence Within and Across Generations," Science, 239, 467-471.

Duncan, G.J., and S. Hoffman (1990): “Welfare Benefits, Economic Opportunities, and Out-ofWedlock Births among Black Teenage Girls,” Demography, 27, 519-535.

Duncan, G.J., and W.J. Yeung (1995): “Extent and Consequences of Welfare Dependence Among America’s Children,” Children and Youth Service Review, 17, 157-182.

Duncan, G.J., W.J. Yeung, J. Brooks-Gunn, and J.R. Smith (1998): “How Much Does Childhood Poverty Affect the Life Chances of Children?” American Sociological Review, 63, 406-423.

Durlauf, S.N., and I. Shaorshadze (2014): “Intergenerational Mobility,” In Emerging Trends in the Social and Behavioral Sciences, R.A. Scott and S.M. Kosslyn (eds.), Sherman Oaks: Sage Publishing, 505-537.

Elango, S., J.L. Garcia, J.J. Heckman, and A. Hojman (2016): “Early Childhood Education,” In Economics of Means-Tested Transfer Programs in the United States, Volume 2, R.A. 
Moffitt (ed.), Chicago: University of Chicago Press and NBER.

Fang, H., and M.P. Keane (2004): “Assessing the Impact of Welfare Reform on Single Mothers,” Brookings Papers on Economic Activity, 1, 1-95.

Fitzgerald, J.M. (2011): “Attrition in Models of Intergenerational Links Using the PSID with Extensions to Health and to Sibling Models," B.E. Journal of Economic Analysis \& Policy, 11, 1-63.

Fitzgerald, J.M., P.T. Gottschalk, and R.A. Moffitt (1998): “An Analysis of Sample Attrition in Panel Data: The Michigan Panel Study of Income Dynamics,” Journal of Human Resources, 33, 251-299.

Freeman, R.B. (1984): “Longitudinal Analyses of the Effects of Trade Unions,” Journal of Labor Economics, 2, 105-128.

Frogner, B., R.A. Moffitt, and D. Ribar (2009): "How Families Are Doing Nine Years after Welfare Reform: 2005 Evidence from the Three-City Study,” In Welfare Reform and its Long-Term Consequences for America's Poor, J.P. Ziliak (ed.), Cambridge University Press, 140-171.

Ganong, P., and J. Liebman (2013): “The Decline, Rebound, and Further Rise in SNAP Enrollment: Disentangling Business Cycle Fluctuations and Policy Changes,” NBER Working Paper 19363.

Gelbach, J. (2004): "Migration, the Life Cycle, and State Benefits: How Low in the Bottom?" Journal of Political Economy, 112, 1091-1130.

Gottschalk, P.T. (1990): “AFDC Participation Across Generations,” American Economic Review: Papers and Proceedings, 80, 367-371. (1992): “The Intergenerational Transmission of Welfare Participation: Facts and Possible Causes," Journal of Policy Analysis and Management, 11, 254-272. 
(1996): "Is the Correlation in Welfare Participation Across Generations Spurious?"

Journal of Public Economics, 63, 1-25.

Gottschalk, P.T., and R.A. Moffitt (1994): "Welfare Dependence: Concepts, Measures, and Trends," American Economic Review: Papers and Proceedings, 84, 38-42.

Grawe, N. (2006): "Lifecycle Bias in Estimates of Intergenerational Earnings Persistence," Labour Economics, 13, 551-570.

Green Book (1994): “Section 10-Aid to Families with Dependent Children.” Background Material and Data on the Programs within the Jurisdiction of the Committee on Ways and Means, U.S. Congress.

Griliches, Z. and Hausman, J.A. (1986): "Errors in Variables in Panel Data," Journal of Econometrics, 31, 93-118.

Grogger, J. (2003): "The Effects of Time Limits, the EITC, and Other Policy Changes on Welfare Use, Work, and Income Among Female-Headed Families,” Review of Economics and Statistics, 85, 394-408.

Grogger, J., and L.A. Karoly (2005): Welfare Reform: Effects of a Decade of Change. Cambridge, MA: Harvard University Press.

Grogger, J., S.J. Haider, and J. Klerman (2003): "Why Did the Welfare Rolls Fall during the 1990s?” American Economic Review: Papers and Proceedings, 93, 288-292.

Haider, S.J., and J. Klerman (2005): “Dynamic Properties of the Welfare Caseload,” Labour Economics, 12, 629-648.

Haider, S.J., and G. Solon (2006): "Life-Cycle Variation in the Association between Current and Lifetime Earnings,” American Economic Review, 96, 1308-1320.

Haskins, R. (2007). Work over Welfare: The Inside Story of the 1996 Welfare Reform Law. 
Washington, DC: Brookings Institution Press.

Hausman, J.A., J. Abrevaya, and F. Scott-Morton (1998): "Misclassification of the Dependent Variable in a Discrete-Response Setting,” Journal of Econometrics, 87, 239-269.

Heckman, J.J. (1978): “Dummy Endogenous Variables in a Simultaneous Equation System,” Econometrica, 46, 931-959.

Hoynes, H., and D. Schanzenbach (2012): "Work Incentives and the Food Stamp Program," Journal of Public Economics, 96, 151-162.

Jenkins, S. (1987): “Snapshots Versus Movies: 'Lifecycle Biases’ and the Estimation of Intergenerational Earnings Inheritance,” European Economic Review, 31, 1149-1158.

Kennan, J., and J.R. Walker (2010): “Wages, Welfare Benefits, and Migration,” Journal of Econometrics, 156, 229-238.

Kreider, B., J.V. Pepper, C. Gundersen, and D. Jolliffe (2012): "Identifying the Effects of SNAP (Food Stamps) on Child Health Outcomes When Participation is Endogenous and Misreported," Journal of the American Statistical Association, 107, 958-975.

Kreider, B., J.V. Pepper, and M. Roy (2016): “Identifying the Effects of WIC on Food Security among Infants and Children,” Southern Economic Journal, 82, 1106-1122.

Kubik, J. (1999): "Incentives for the Identification and Treatment of Children with Disabilities: The Supplemental Security Income Program,” Journal of Public Economics, 73, 187-215.

Lee, C., and G. Solon. (2009). "Trends in Intergenerational Income Mobility," Review of Economics and Statistics, 91, 766-772.

Levine, P.B. and D.J. Zimmerman (1996): “The Intergenerational Correlation in AFDC Participation: Welfare Trap or Poverty Trap?” Discussion paper, University of Wisconsin Institute for Research on Poverty. 
(1999): “An Empirical Analysis of the Welfare Magnet Debate Using the NLSY,"

Journal of Population Economics, 12, 391-409.

_ (2005): “Children's Welfare Exposure and Subsequent Development," Journal of Public Economics, 89, 31-56.

Lopoo, L. (2007): "Fertility Trends, Maternal Characteristics, and Poverty in the American South,” Journal of Poverty, 11, 23-46.

Manski, C.F. (1995): Identification Problems in the Social Sciences. Cambridge, MA: Harvard University Press.

Mazumder, B. (2005): "Fortunate Sons: New Estimates of Intergenerational Mobility in the U.S. Using Social Security Earnings Data,” Review of Economics and Statistics, 87, 235-255. McKinnish, T. (2007): “Cross-Border Welfare Migration: New Evidence from Micro Data,” Journal of Public Economics, 91, 437-450.

McLanahan, S. (1988). "Family Structure and Dependency: Early Transitions to Female Household Headship,” Demography, 25, 1-16.

Meyer, B., and N. Mittag (2014): “Misclassification in Binary Choice Models,” NBER Working Paper 20509.

(2015): “Using Linked Survey and Administrative Data to Better Measure Income: Implications for Poverty, Program Effectiveness, and Holes in the Safety Net,” NBER Working Paper 21676.

Meyer, B., R. Goerge, and N. Mittag (2014): "Errors in Survey Reporting and Imputation and their Effects on Estimates of Food Stamp Program Participation," Mimeo.

Meyer, B., W. Mok, and J. Sullivan (2015a): “Household Surveys in Crisis,” Journal of Economic Perspectives, 29, 199-226. 
(2015b): “The Under-Reporting of Transfers in Household Surveys: Its Nature and

Consequences,” NBER Working Paper 15181. Updated version June 2015.

Moffitt, R.A. (1983): “An Economic Model of Welfare Stigma,” American Economic Review, $73,1023-1035$.

— (1992): "Incentive Effects of the U.S. Welfare System: A Review," Journal of Economic Literature, 30, 1-61.

_ (2003): “Temporary Assistance for Needy Families,” In Means-Tested Transfer

Programs in the United States, R.A. Moffitt (ed.), Chicago: University of Chicago Press.

Moffitt, R.A., and P.T. Gottschalk (2002): “Trends in the Transitory Variance of Earnings in the United States,” Economic Journal, 112, C68-C73.

Molinari, F. (2008): "Partial Identification of Probability Distributions with Misclassified Data," Journal of Econometrics, 144, 81-117.

Murray, C. (1984). Losing Ground: American Social Policy, 1950-1980. New York: Basic Books.

Nybom, M., and J. Stuhler (2016): "Heterogeneous Income Profiles and Life-Cycle Bias in Intergenerational Mobility Estimation,” Journal of Human Resources, 51, 239-268.

Page, M.E. (2004): "New Evidence on the Intergenerational Correlation in Welfare Participation," In Generational Income Mobility in North America and Europe, M. Corak (ed.), Cambridge University Press, 226-244.

Pepper, J.V. (2000): “The Intergenerational Transmission of Welfare Receipt: A Nonparametric Bounds Analysis," Review of Economics and Statistics, 82, 472-488.

Schmidt, L. and P. Sevak (2004): “AFDC, SSI, and Welfare Reform Aggressiveness: Caseload Reductions vs. Caseload Shifting,” Journal of Human Resources, 39, 792-812.

Smith, J.P., and F.R. Welch (1989): "Black Economic Progress after Myrdal,” Journal of 
Economic Literature, 27, 519-564.

Solon, G. (1992): “Intergenerational Income Mobility in the United States,” American Economic Review, 82, 393-408.

(1999): "Intergenerational Mobility in the Labor Market," In Handbook of Labor Economics,

Volume 3A, O. Ashenfelter and D. Card (eds.), Amsterdam: North Holland, 1761-1800.

Solon, G., M. Corcoran, R. Gordon, and D. Laren (1988): "Sibling and Intergenerational Correlations in Welfare Program Participation,” Journal of Human Resources, 23, 388-396.

Solon, G., S.J. Haider, and J.M. Wooldridge (2015): “What Are We Weighting For?” Journal of Human Resources, 50, 301-316.

Wolfe, B.L., R. Haveman, D. Ginther, and C.B. An (1996): “The ‘Window Problem' in Studies of Children's Attainments: A Methodological Exploration,” Journal of the American Statistical Association, 91, 970-982.

Ziliak, J.P. (2007): "Making Work Pay: Changes in Effective Tax Rates and Guarantees in U.S. Transfer Programs, 1983-2002,” Journal of Human Resources, 42, 619-642. (2015): "Why Are So Many Americans on Food Stamps? The Role of the Economy, Policy, and Demographics," In SNAP Matters: How Food Stamps Affect Health and Well Being, J. Bartfeld, C. Gundersen, T. Smeeding, and J.P. Ziliak (eds.), Stanford, CA: Stanford University Press, 18-48. (2016): “Temporary Assistance for Needy Families,” In Economics of Means-Tested Transfer Programs in the United States, Volume 1, R.A. Moffitt (ed.), University of Chicago Press.

Ziliak, J.P., D. Figlio, E. Davis, and L. Connolly (2000): “Accounting for the Decline in AFDC Caseloads: Welfare Reform or the Economy?” Journal of Human Resources, 35, 570-586. 
Zimmerman, D.J. (1992): "Regression Toward Mediocrity in Economic Stature,” American Economic Review, 82, 409-429.

Ziol-Guest, K.M., G.J. Duncan, A. Kalil, and W.T. Boyce (2012): "Early Childhood Poverty, Immune-Mediated Disease Processes, and Adult Productivity," Proceedings of the National Academy of Sciences, 109, 17289-17293. 
FIGURE 1. TRENDS IN AFDC/TANF, FOOD STAMP/SNAP, AND SSI RECIPIENTS

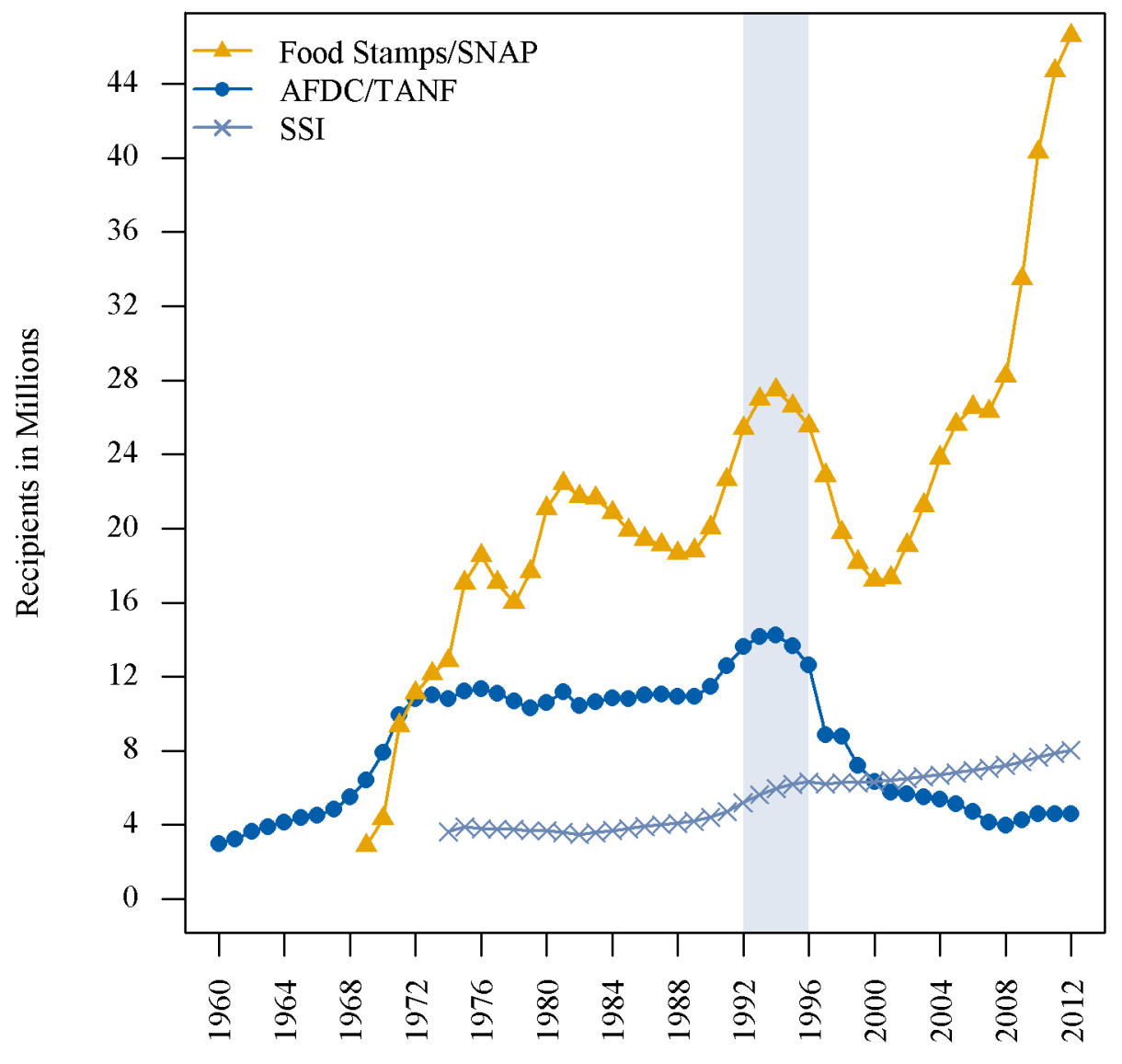

Year

Notes: Authors' tabulations of data collected from the U.S. Department of Health and Human Services, U.S. Department of Agriculture, and Social Security Administration. The major waiver period of welfare reform is indicated by the shaded region. Abbreviations: Aid to Families with Dependent Children/Temporary Assistance for Needy Families

(AFDC/TANF), Supplemental Nutrition Assistance Program (SNAP), and Supplemental Security Income (SSI). 
Figure 2. TRENDS IN THE INTERGENERATIONAL CORRELATION OF WELFARE PARTICIPATION

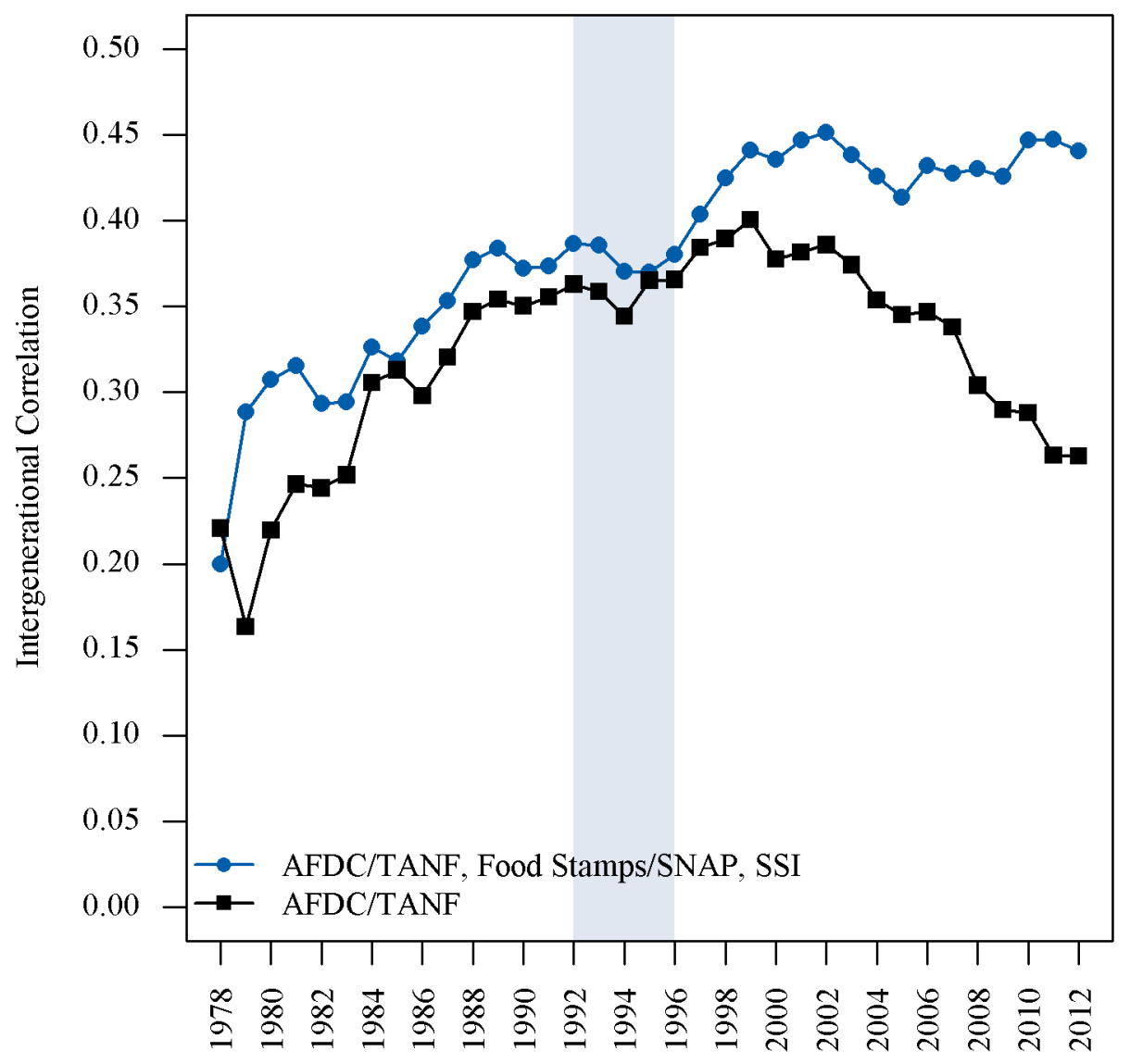

Year

Notes: The dependent variable for is an indicator for whether a daughter ever participated in AFDC/TANF (or AFDC/TANF, SSI, or Food Stamps) in any year after forming her own family through age 27. The independent variable is an indicator for whether the mother ever participated in AFDC/TANF when the child is observed living at home. These trends reflect rolling cohort groups of daughters aged 27-42 in each year. The major waiver period of welfare reform is indicated by the shaded region. Abbreviations: Aid to Families with Dependent Children/Temporary Assistance for Needy Families (AFDC/TANF), Supplemental Nutrition Assistance Program (SNAP), and Supplemental Security Income (SSI). 
Figure 3. CRITICAL EXPOSURE PERIOD FOR AFDC/TANF TRANSMISSION THROUGH AgE 17
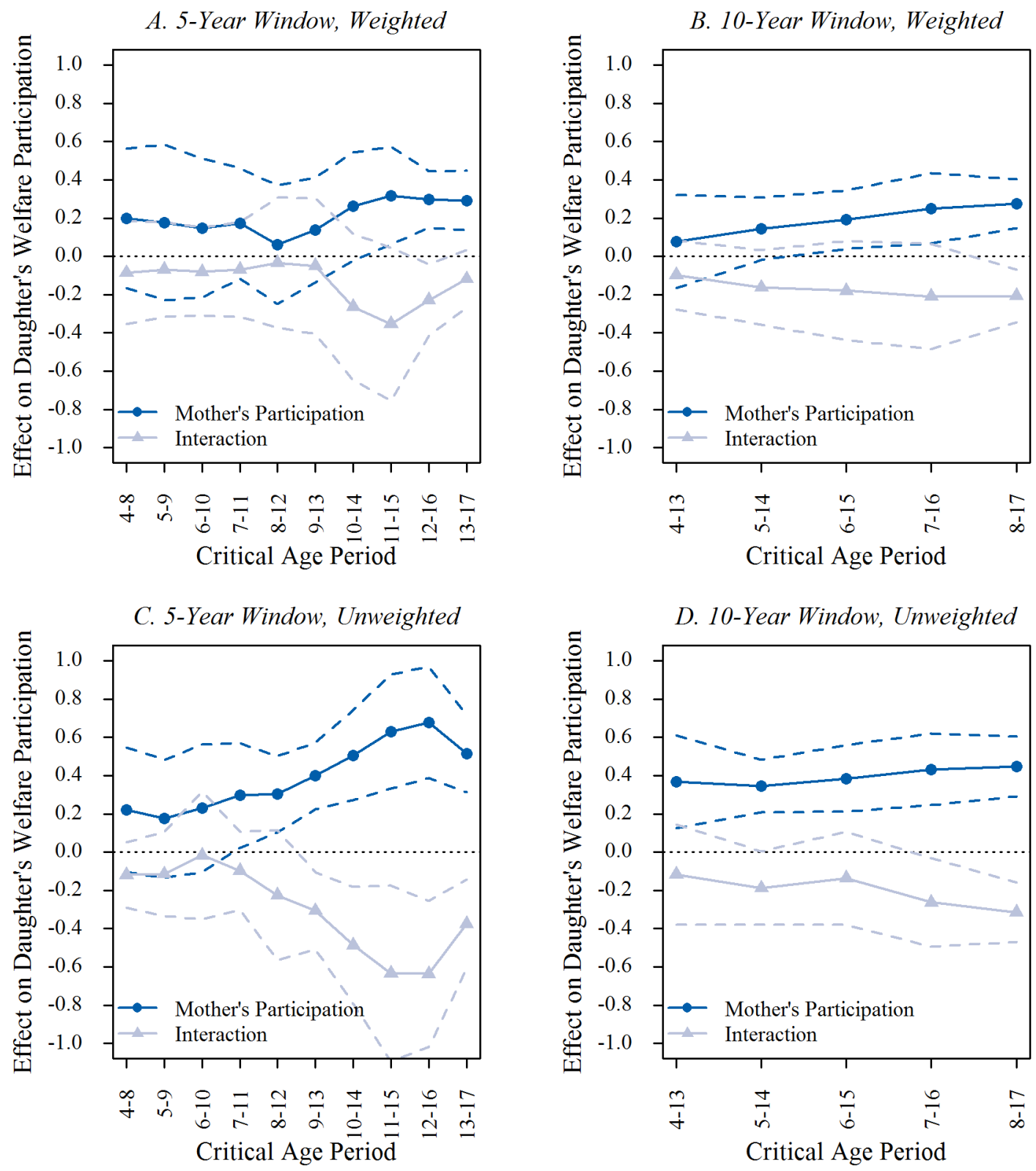

Notes: The dependent variable is daughter's current AFDC/TANF status, and the independent variables include any previous AFDC/TANF participation for the mother, an indicator for after welfare reform, an interaction term for mother's participation after welfare reform, state and year effects, daughter time-varying controls, and instrumental variables including the average and maximum of mother's AFDC/TANF benefit standard and federal/state EITC maximum benefit by family size during the daughter's ages $12-18$, and interactions of each with an indicator for welfare reform. 
Figure 4. TRENDS IN INTERGENERATIONAL TRANSMISSION OF POVERTy STATUS AND FAMILy INCOME

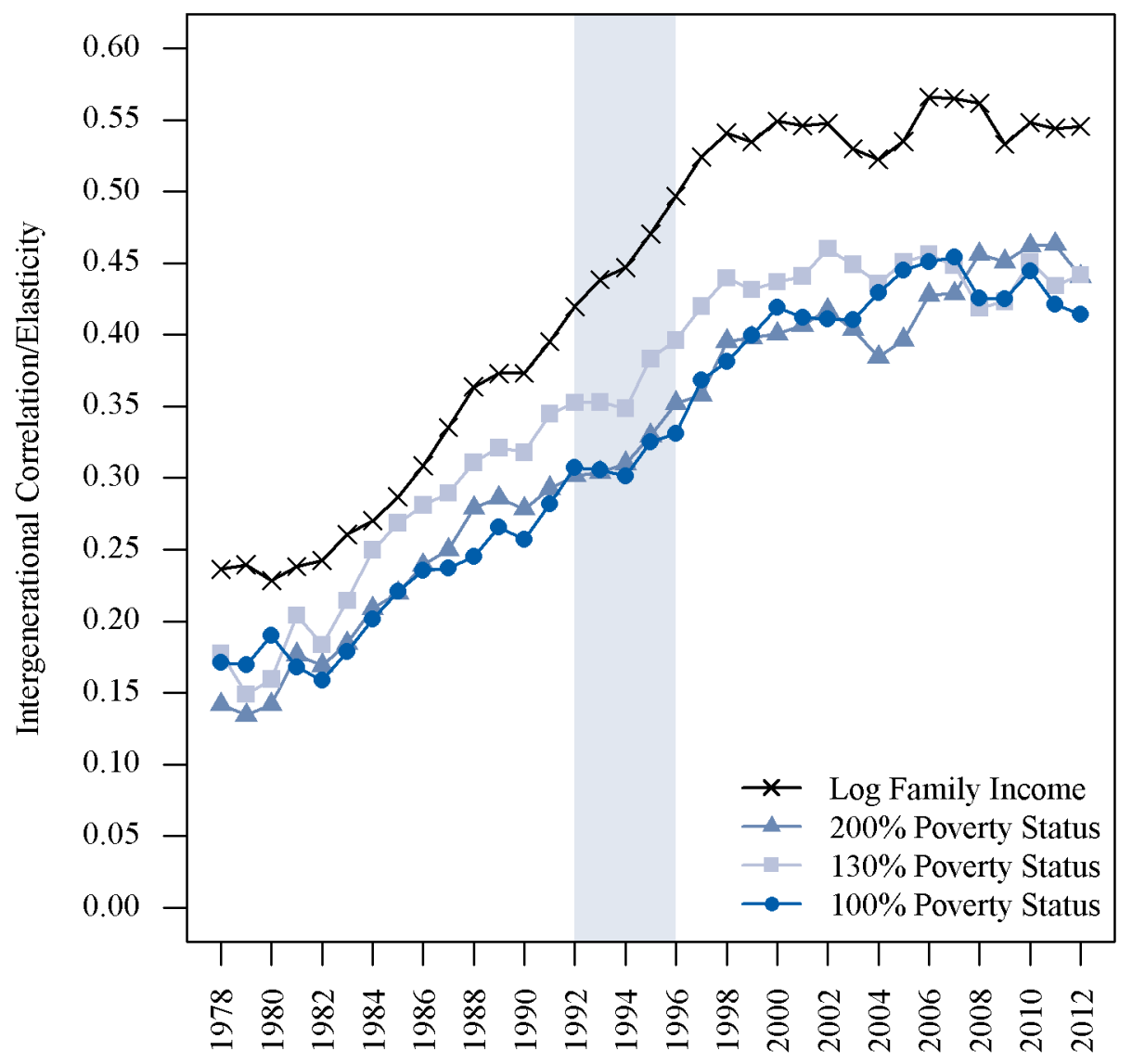

Year

Notes: The intergenerational transmission for poverty status represents linear probability model estimates based on indicators for whether an individual's mean family income is equal to or below 100,130 , or $200 \%$ of the mean federal poverty threshold by age 27 , and the intergenerational elasticity of family income is based on a log-log model of a daughter's average income through age 27 and the average of all of her mother's family income. The major waiver period of welfare reform is indicated by the shaded region. 
TABlE 1. Descriptive Statistics

\begin{tabular}{|c|c|c|c|}
\hline A. Daughter's Characteristics & Before Reform & After Reform & Pooled \\
\hline \multicolumn{4}{|l|}{ Currently Receiving Welfare? (\%) } \\
\hline \multirow[t]{2}{*}{ AFDC/TANF } & 0.080 & 0.025 & 0.044 \\
\hline & $(0.271)$ & $(0.157)$ & $(0.206)$ \\
\hline \multirow[t]{2}{*}{ AFDC/TANF, Food Stamps/SNAP, SSI } & 0.132 & 0.112 & 0.119 \\
\hline & $(0.338)$ & $(0.315)$ & $(0.323)$ \\
\hline \multirow[t]{2}{*}{ Years Before/After Welfare Reform (\%) } & 0.348 & 0.652 & \\
\hline & $(0.476)$ & $(0.476)$ & \\
\hline \multirow[t]{2}{*}{ Age } & 28.245 & 38.665 & 35.041 \\
\hline & $(5.573)$ & $(9.009)$ & $(9.400)$ \\
\hline \multirow[t]{2}{*}{ Number of Children } & 1.249 & 1.191 & 1.211 \\
\hline & $(1.168)$ & $(1.280)$ & $(1.243)$ \\
\hline \multicolumn{4}{|l|}{ Race } \\
\hline \multirow[t]{2}{*}{ Black (\%) } & 0.161 & 0.170 & 0.167 \\
\hline & $(0.368)$ & $(0.375)$ & $(0.373)$ \\
\hline \multirow[t]{2}{*}{ White $(\%)$} & 0.812 & 0.805 & 0.807 \\
\hline & $(0.391)$ & $(0.396)$ & $(0.394)$ \\
\hline \multirow[t]{2}{*}{ Other $(\%)$} & 0.027 & 0.025 & 0.026 \\
\hline & $(0.162)$ & $(0.157)$ & $(0.159)$ \\
\hline \multirow[t]{2}{*}{ Resides in Same State as Birth (\%) } & 0.759 & 0.703 & 0.723 \\
\hline & $(0.428)$ & $(0.457)$ & $(0.448)$ \\
\hline B. Mother's Characteristics & Before Reform & After Reform & Pooled \\
\hline \multicolumn{4}{|l|}{ Any Previous Welfare? (\%) } \\
\hline \multirow[t]{2}{*}{ AFDC/TANF } & 0.269 & 0.067 & 0.272 \\
\hline & $(0.444)$ & $(0.251)$ & $(0.445)$ \\
\hline \multirow[t]{2}{*}{ AFDC/TANF, Food Stamps/SNAP, SSI } & 0.429 & 0.191 & 0.435 \\
\hline & $(0.495)$ & $(0.393)$ & $(0.496)$ \\
\hline \multirow[t]{2}{*}{ Years Before/After Welfare Reform (\%) } & 0.858 & 0.142 & \\
\hline & $(0.158)$ & $(0.158)$ & \\
\hline \multirow[t]{2}{*}{ Age } & 42.540 & 59.340 & 61.429 \\
\hline & $(8.871)$ & $(10.503)$ & $(11.426)$ \\
\hline \multirow[t]{2}{*}{ AFDC/TANF Benefit Standard, Average } & 723.889 & 393.179 & 713.117 \\
\hline & $(339.777)$ & $(213.517)$ & $(341.339)$ \\
\hline \multirow[t]{2}{*}{ AFDC/TANF Benefit Standard, Maximum } & 900.850 & 477.023 & 892.270 \\
\hline & $(369.241)$ & $(225.612)$ & $(370.140)$ \\
\hline \multirow[t]{2}{*}{ EITC Federal/State Benefit, Average } & 801.914 & 3223.785 & 877.024 \\
\hline & $(726.252)$ & $(1412.117)$ & $(876.294)$ \\
\hline \multirow[t]{2}{*}{ EITC Federal/State Benefit, Maximum } & 1209.281 & 3883.471 & 1320.374 \\
\hline & $(886.228)$ & $(1405.078)$ & $(1087.700)$ \\
\hline \multicolumn{3}{|l|}{ Mean Mother-Child Family Observations } & 14.212 \\
\hline \multicolumn{2}{|l|}{ Mean Daughter-as-Adult Observations } & & 25.100 \\
\hline Total Observations & 25323 & 30744 & 56067 \\
\hline \multicolumn{4}{|c|}{$\begin{array}{l}\text { Notes: Sample averages are weighted by the daughter's PSID core longitudinal weights for both daughters' and mothers' } \\
\text { statistics. Further, the pooled statistics for mothers are not a simple weighted average of before/after reform given that } \\
\text { these data are aggregated by time period. For example, the pooled average for any previous welfare is cumulative over } \\
\text { pre- and post-reform periods, whereas the pooled average for age represents mother's age in the daughter's observation } \\
\text { year as opposed to prior years of mother's potential welfare participation as shown in the before/after reform columns. }\end{array}$} \\
\hline
\end{tabular}


TABLE 2. INTERGENERATIONAL TRANSMISSION OF AFDC/TANF PARTICIPATION

\begin{tabular}{|c|c|c|c|c|}
\hline & (1) & (2) & (3) & (4) \\
\hline \multirow[t]{3}{*}{ Mother's Participation } & 0.145 & 0.238 & 0.236 & 0.355 \\
\hline & $(0.014)$ & $(0.054)$ & $(0.022)$ & $(0.087)$ \\
\hline & [0.203] & {$[0.364]$} & {$[0.312]$} & {$[0.557]$} \\
\hline \multirow[t]{3}{*}{ After Welfare Reform } & 0.036 & 0.060 & 0.047 & 0.068 \\
\hline & $(0.007)$ & $(0.018)$ & $(0.014)$ & $(0.027)$ \\
\hline & {$[0.077]$} & [0.139] & {$[0.088]$} & {$[0.161]$} \\
\hline \multirow{3}{*}{$\begin{array}{c}\text { Mother's Participation } \times \\
\text { After Welfare Reform }\end{array}$} & -0.101 & -0.164 & -0.134 & -0.181 \\
\hline & $(0.015)$ & $(0.045)$ & $(0.030)$ & $(0.071)$ \\
\hline & {$[-0.159]$} & {$[-0.260]$} & {$[-0.202]$} & {$[-0.313]$} \\
\hline Instrumental Variables & No & Yes & No & Yes \\
\hline Misclassification Correction & No & No & Yes & Yes \\
\hline Weak IV Test Statistic & & 23.157 & & 20.875 \\
\hline p-value (Weak IV) & & 0.002 & & 0.004 \\
\hline Hansen J Statistic & & 2.548 & & 2.493 \\
\hline p-value (J Statistic) & & 0.863 & & 0.869 \\
\hline Percent Change in Levels & $-70 \%$ & $-69 \%$ & $-57 \%$ & $-51 \%$ \\
\hline Percent Change over Baseline & $-47 \%$ & $-45 \%$ & $-40 \%$ & $-32 \%$ \\
\hline Number of Daughters & 2961 & 2961 & 2961 & 2961 \\
\hline Observations & 56067 & 56067 & 56067 & 56067 \\
\hline \multicolumn{5}{|c|}{$\begin{array}{l}\text { Notes: Weighted estimates are shown with unweighted versions of point estimates below in brackets. Robust standard } \\
\text { errors with state clustering are shown in parentheses. All specifications control for state and year effects in addition to } \\
\text { time-varying controls for daughter's age, age squared, and indicators for number of children equal to } 1,2,3 \text {, or at least } \\
\text { 4. Instrumental variables include the average and maximum of mother's AFDC/TANF benefit standard and } \\
\text { federal/state EITC by family size during the critical exposure period of daughter's ages } 12-18 \text {, and interactions of each } \\
\text { with an indicator for welfare reform. The weak IV test statistic is a Kleibergen-Paap (2006) rank statistic. }\end{array}$} \\
\hline
\end{tabular}


TABLE 3. IV ESTIMATES OF THE INTERGENERATIONAL TRANSMISSION OF AFDC/TANF PARTICIPATION BY MiNiMUM NUMBER OF MOTHER-DAUGHTER FAMILY OBSERVATIONS, $\boldsymbol{N}_{\boldsymbol{F}}$

\begin{tabular}{|c|c|c|c|c|c|c|}
\hline & \multicolumn{2}{|c|}{$N_{F} \geq 1$} & \multicolumn{2}{|c|}{$N_{F} \geq 10$} & \multicolumn{2}{|c|}{$N_{F} \geq 15$} \\
\hline & (1) & (2) & (3) & (4) & (5) & (6) \\
\hline \multirow[t]{3}{*}{ Mother's Participation } & 0.284 & 0.424 & 0.296 & 0.492 & 0.281 & 0.462 \\
\hline & $(0.062)$ & $(0.104)$ & $(0.066)$ & $(0.107)$ & $(0.063)$ & $(0.111)$ \\
\hline & {$[0.402]$} & {$[0.584]$} & {$[0.375]$} & {$[0.615]$} & {$[0.393]$} & [0.612] \\
\hline \multirow[t]{3}{*}{ After Welfare Reform } & 0.075 & 0.091 & 0.084 & 0.116 & 0.086 & 0.115 \\
\hline & $(0.021)$ & $(0.035)$ & $(0.024)$ & $(0.036)$ & $(0.027)$ & $(0.045)$ \\
\hline & {$[0.167]$} & [0.189] & {$[0.145]$} & {$[0.181]$} & {$[0.167]$} & [0.198] \\
\hline \multirow{3}{*}{$\begin{array}{c}\text { Mother's Participation } \times \\
\text { After Welfare Reform }\end{array}$} & -0.211 & -0.253 & -0.228 & -0.319 & -0.191 & -0.250 \\
\hline & $(0.053)$ & $(0.087)$ & $(0.059)$ & $(0.095)$ & $(0.059)$ & $(0.105)$ \\
\hline & {$[-0.329]$} & {$[-0.392]$} & {$[-0.267]$} & {$[-0.350]$} & {$[-0.296]$} & {$[-0.370]$} \\
\hline Misclassification Correction & No & Yes & No & Yes & No & Yes \\
\hline Weak IV Test Statistic & 20.812 & 18.441 & 23.667 & 23.094 & 16.917 & 17.672 \\
\hline p-value (Weak IV) & 0.004 & 0.010 & 0.001 & 0.002 & 0.018 & 0.014 \\
\hline Hansen J Statistic & 4.284 & 4.980 & 5.289 & 5.166 & 4.364 & 4.888 \\
\hline p-value (J Statistic) & 0.638 & 0.546 & 0.507 & 0.523 & 0.628 & 0.558 \\
\hline Percent Change in Levels & $-74 \%$ & $-60 \%$ & $-77 \%$ & $-65 \%$ & $-68 \%$ & $-54 \%$ \\
\hline Percent Change over Baseline & $-55 \%$ & $-44 \%$ & $-60 \%$ & $-51 \%$ & $-44 \%$ & $-36 \%$ \\
\hline Number of Daughters & 3823 & 3823 & 2466 & 2466 & 1806 & 1806 \\
\hline Observations & 74548 & 74548 & 43732 & 43732 & 28902 & 28902 \\
\hline \multicolumn{7}{|c|}{$\begin{array}{l}\text { Notes: Weighted estimates are shown with unweighted versions of point estimates below in brackets. The minimum } \\
\text { number of mother-daughter family observations, denoted } N_{F} \text {, represent years when the mother is observed before the } \\
\text { daughter has formed her own family unit (for estimates in all other tables, } N_{F} \geq 5 \text { ). Robust standard errors with state } \\
\text { clustering are shown in parentheses. All specifications control for state and year effects in addition to time-varying } \\
\text { controls for daughter's age, age squared, and indicators for number of children equal to } 1,2,3 \text {, or at least } 4 \text {. } \\
\text { Instrumental variables used in each specification include the average and maximum of mother's AFDC/TANF benefit } \\
\text { standard and federal/state EITC by family size during the critical exposure period of daughter's ages } 12-18 \text {, and } \\
\text { interactions of each with an indicator for welfare reform. The weak IV test statistic is a Kleibergen-Paap (2006) rank } \\
\text { statistic. }\end{array}$} \\
\hline
\end{tabular}


TABLE 4. INTERGENERATIONAL TRANSMISSION OF AFDC/TANF PARTICIPATION WITH LEE-SOLON-TYPE (2009) LIFE-CYCLE ADJUSTMENTS

\begin{tabular}{|c|c|c|c|c|}
\hline & (1) & (2) & (3) & (4) \\
\hline \multirow[t]{3}{*}{ Mother's Participation } & 0.177 & 0.333 & 0.257 & 0.489 \\
\hline & $(0.017)$ & $(0.066)$ & $(0.025)$ & $(0.098)$ \\
\hline & [0.237] & {$[0.431]$} & {$[0.328]$} & {$[0.570]$} \\
\hline \multirow[t]{3}{*}{ After Welfare Reform } & 0.018 & 0.040 & 0.022 & 0.037 \\
\hline & $(0.007)$ & $(0.014)$ & $(0.013)$ & $(0.024)$ \\
\hline & [0.037] & [0.118] & [0.041] & [0.196] \\
\hline \multirow{3}{*}{$\begin{array}{c}\text { Mother's Participation } \times \\
\text { After Welfare Reform }\end{array}$} & -0.117 & -0.159 & -0.126 & -0.177 \\
\hline & $(0.024)$ & $(0.049)$ & $(0.044)$ & $(0.079)$ \\
\hline & {$[-0.171]$} & {$[-0.279]$} & {$[-0.184]$} & {$[-0.386]$} \\
\hline Instrumental Variables & No & Yes & No & Yes \\
\hline Misclassification Correction & No & No & Yes & Yes \\
\hline Weak IV Test Statistic & & 26.617 & & 23.252 \\
\hline p-value (Weak IV) & & 0.032 & & 0.079 \\
\hline Hansen J Statistic & & 19.595 & & 17.378 \\
\hline p-value (J Statistic) & & 0.143 & & 0.237 \\
\hline Percent Change in Levels & $-66 \%$ & $-48 \%$ & $-49 \%$ & $-36 \%$ \\
\hline Percent Change over Baseline & $-40 \%$ & $-8 \%$ & $-29 \%$ & $-11 \%$ \\
\hline Number of Daughters & 2961 & 2961 & 2961 & 2961 \\
\hline Observations & 56067 & 56067 & 56067 & 56067 \\
\hline \multicolumn{5}{|c|}{$\begin{array}{l}\text { Notes: Weighted estimates are shown with unweighted versions of point estimates below in brackets. Robust standard } \\
\text { errors with state clustering are shown in parentheses. Lee-Solon-type control variables are used in each specification: a } \\
\text { quartic on mother's mean age during prior years of potential welfare participation, a quartic on daughter's current age } \\
\text { detrended by } 25 \text { (current age - 25), and mother's participation indicator interacted with the quartic on daughter's age. } \\
\text { All specifications control for state and year effects in addition to time-varying indicators for daughter's number of } \\
\text { children equal to } 1,2,3 \text {, or at least } 4 \text {. Instrumental variables include the average and maximum of mother's } \\
\text { AFDC/TANF benefit standard and federal/state EITC by family size during the critical exposure period of daughter's } \\
\text { ages } 12-18 \text {, and interactions of each with an indicator for welfare reform. Further instrumental variables accounting for } \\
\text { age adjustments include interactions of each instrument above measured by averages (not maximums) with a quartic in } \\
\text { daughter's detrended age. The weak IV test statistic is a Kleibergen-Paap (2006) rank statistic. }\end{array}$} \\
\hline
\end{tabular}


TABLE 5. IV ESTIMATES OF INTERGENERATIONAL TRANSMISSION OF AFDC/TANF PARTICIPATION BY DAUGHTER's GEOGRAPHIC MOBILITY STATUS

\begin{tabular}{|c|c|c|c|c|c|c|}
\hline & \multicolumn{2}{|c|}{ Same State as Birth } & \multicolumn{2}{|c|}{ Same State as Mother } & \multicolumn{2}{|c|}{ Never Moves States } \\
\hline & (1) & (2) & (3) & (4) & (5) & (6) \\
\hline \multirow[t]{3}{*}{ Mother's Participation } & 0.279 & 0.443 & 0.363 & 0.506 & 0.373 & 0.580 \\
\hline & $(0.072)$ & $(0.123)$ & $(0.081)$ & $(0.131)$ & $(0.089)$ & $(0.141)$ \\
\hline & {$[0.415]$} & {$[0.641]$} & {$[0.498]$} & {$[0.706]$} & {$[0.476]$} & {$[0.736]$} \\
\hline \multirow[t]{3}{*}{ After Welfare Reform } & 0.069 & 0.081 & 0.074 & 0.079 & 0.098 & 0.122 \\
\hline & $(0.025)$ & $(0.041)$ & $(0.019)$ & $(0.034)$ & $(0.037)$ & $(0.057)$ \\
\hline & {$[0.155]$} & {$[0.170]$} & {$[0.161]$} & {$[0.182]$} & {$[0.186]$} & {$[0.216]$} \\
\hline \multirow{3}{*}{$\begin{array}{c}\text { Mother's Participation } \times \\
\text { After Welfare Reform }\end{array}$} & -0.191 & -0.208 & -0.249 & -0.254 & -0.274 & -0.320 \\
\hline & $(0.063)$ & $(0.104)$ & $(0.068)$ & $(0.114)$ & $(0.083)$ & $(0.126)$ \\
\hline & {$[-0.281]$} & {$[-0.319]$} & {$[-0.343]$} & {$[-0.373]$} & {$[-0.347]$} & {$[-0.417]$} \\
\hline Misclassification Correction & No & Yes & No & Yes & No & Yes \\
\hline Weak IV Test Statistic & 18.593 & 18.153 & 18.683 & 17.286 & 12.985 & 13.173 \\
\hline p-value (Weak IV) & 0.010 & 0.011 & 0.009 & 0.016 & 0.073 & 0.068 \\
\hline Hansen J Statistic & 4.031 & 3.389 & 3.297 & 3.074 & 3.903 & 3.942 \\
\hline p-value (J Statistic) & 0.673 & 0.759 & 0.771 & 0.799 & 0.690 & 0.685 \\
\hline Percent Change in Levels & $-68 \%$ & $-47 \%$ & $-69 \%$ & $-50 \%$ & $-73 \%$ & $-55 \%$ \\
\hline Percent Change over Baseline & $-44 \%$ & $-26 \%$ & $-45 \%$ & $-31 \%$ & $-53 \%$ & $-38 \%$ \\
\hline Number of Daughters & 2617 & 2617 & 2757 & 2757 & 1960 & 1960 \\
\hline Observations & 44114 & 44114 & 36818 & 36818 & 36396 & 36396 \\
\hline $\begin{array}{l}\text { Notes: Weighted estimates are sho } \\
\text { errors with state clustering are shov } \\
\text { time-varying controls for daughter' } \\
4 . \text { Instrumental variables used in ea } \\
\text { benefit standard and federal/state } \mathrm{E} \\
\text { interactions of each with an indicat } \\
\text { statistic. }\end{array}$ & $\begin{array}{l}\text { h with unw } \\
\text { age, age sc } \\
\text { h specifica } \\
\text { TC by fami }\end{array}$ & $\begin{array}{l}\text { hted versi } \\
\text { s. All spe } \\
\text { ed, and in } \\
\text { include t } \\
\text { ize during }\end{array}$ & $\begin{array}{l}\text { of point es } \\
\text { ations cor } \\
\text { tors for nu } \\
\text { verage anc } \\
\text { critical ex }\end{array}$ & $\begin{array}{l}\text { tes below } \\
\text { for state ar } \\
\mathrm{r} \text { of childr } \\
\text { ximum of } \\
\text { are period }\end{array}$ & $\begin{array}{l}\text { rackets. Ro } \\
\text { year effects } \\
\text { equal to } 1, \\
\text { ther's AFD } \\
\text { daughter's a }\end{array}$ & $\begin{array}{l}\text { st standard } \\
\text { addition to } \\
\text { or at least } \\
\text { ANF } \\
12-18 \text {, and } \\
\text { 06) rank }\end{array}$ \\
\hline
\end{tabular}


TABLE 6. INTERGENERATIONAL TRANSMISSION OF AFDC/TANF PARTICIPATION BY EXPOSURE MECHANISM VIA "WORD OF MOUTH"

\begin{tabular}{|c|c|c|c|c|c|}
\hline & \multicolumn{2}{|c|}{$\begin{array}{c}\text { Exposure During } \\
\text { Co-Residence Only }\end{array}$} & \multicolumn{3}{|c|}{$\begin{array}{l}\text { Any Prior Exposure with } \\
\text { Daughter Fixed Effects and } \\
\text { "Word-of-Mouth" Learning }\end{array}$} \\
\hline & (1) & (2) & (3) & (4) & $(5)$ \\
\hline \multirow[t]{3}{*}{ Mother's Participation } & 0.252 & 0.381 & 0.079 & 0.217 & -0.143 \\
\hline & $(0.047)$ & $(0.076)$ & $(0.023)$ & $(0.032)$ & $(0.364)$ \\
\hline & [0.408] & [0.617] & [0.119] & [0.281] & [0.142] \\
\hline \multirow[t]{3}{*}{ After Welfare Reform } & 0.053 & 0.061 & 0.052 & 0.072 & 0.168 \\
\hline & $(0.017)$ & $(0.028)$ & $(0.011)$ & $(0.020)$ & $(0.047)$ \\
\hline & [0.121] & [0.129] & [0.106] & [0.137] & [0.214] \\
\hline \multirow{3}{*}{$\begin{array}{l}\text { Mother's Participation } \times \\
\text { After Welfare Reform }\end{array}$} & -0.171 & -0.185 & -0.128 & -0.176 & -0.511 \\
\hline & $(0.054)$ & $(0.093)$ & $(0.019)$ & $(0.034)$ & $(0.128)$ \\
\hline & {$[-0.266]$} & {$[-0.288]$} & {$[-0.162]$} & {$[-0.210]$} & {$[-0.380]$} \\
\hline Daughter Fixed Effects & No & No & Yes & Yes & Yes \\
\hline Instrumental Variables & Yes & Yes & No & No & Yes \\
\hline Misclassification Correction & No & Yes & No & Yes & Yes \\
\hline Weak IV Test Statistic & 17.908 & 17.780 & & & 20.387 \\
\hline p-value (Weak IV) & 0.012 & 0.013 & & & 0.005 \\
\hline Hansen J Statistic & 5.387 & 5.114 & & & 11.896 \\
\hline p-value (J Statistic) & 0.495 & 0.529 & & & 0.064 \\
\hline Percent Change in Levels & $-68 \%$ & $-49 \%$ & $-100 \%$ & $-81 \%$ & - \\
\hline Percent Change over Baseline & $-43 \%$ & $-28 \%$ & - & $-74 \%$ & - \\
\hline Number of Daughters & 2961 & 2961 & 2961 & 2961 & 2961 \\
\hline Observations & 56067 & 56067 & 56067 & 56067 & 56067 \\
\hline \multicolumn{6}{|c|}{$\begin{array}{l}\text { Notes: Weighted estimates are shown with unweighted versions of point estimates below in brackets. Robust standard } \\
\text { errors with state clustering are shown in parentheses. All specifications control for state and year effects in addition to } \\
\text { time-varying controls for daughter's age, age squared, and indicators for number of children equal to } 1,2,3 \text {, or at least } \\
\text { 4. Instrumental variables include the average and maximum of mother's AFDC/TANF benefit standard and federal/ } \\
\text { state EITC by family size during years of co-residence for columns (1)-(2) or during any prior year up to a 5-year lag } \\
\text { for column (4), and interactions of each with an indicator for welfare reform. The weak IV test statistic is a Kleibergen- } \\
\text { Paap (2006) rank statistic. }\end{array}$} \\
\hline
\end{tabular}


TABLE 7. INTERGENERATIONAL TRANSMISSION OF AFDC/TANF PARTICIPATION BY DURATION OF MOTHER'S PARTICIPATION IN YEARS

\begin{tabular}{|c|c|c|c|c|}
\hline & (1) & (2) & (3) & (4) \\
\hline \multirow{3}{*}{$\begin{array}{l}\text { Mother's Participation, } \\
\text { At Most } 2 \text { Years }\end{array}$} & 0.112 & 0.123 & 0.175 & 0.139 \\
\hline & $(0.026)$ & $(0.169)$ & $(0.043)$ & $(0.282)$ \\
\hline & {$[0.157]$} & [0.109] & {$[0.240]$} & [0.155] \\
\hline \multirow{3}{*}{$\begin{array}{l}\text { Mother's Participation, } \\
\text { More than } 2 \text { Years }\end{array}$} & 0.195 & 0.279 & 0.320 & 0.414 \\
\hline & $(0.028)$ & $(0.099)$ & $(0.046)$ & $(0.153)$ \\
\hline & {$[0.235]$} & [0.461] & {$[0.363]$} & {$[0.674]$} \\
\hline \multirow[t]{3}{*}{ After Welfare Reform } & 0.028 & 0.037 & 0.034 & 0.033 \\
\hline & $(0.008)$ & $(0.015)$ & $(0.015)$ & $(0.024)$ \\
\hline & [0.049] & {$[0.090]$} & {$[0.047]$} & [0.093] \\
\hline \multirow{3}{*}{$\begin{array}{l}\text { Participation At Most } 2 \text { Years } \times \\
\text { After Welfare Reform }\end{array}$} & -0.063 & -0.057 & -0.066 & 0.053 \\
\hline & $(0.030)$ & $(0.187)$ & $(0.055)$ & $(0.324)$ \\
\hline & {$[-0.114]$} & {$[-0.122]$} & {$[-0.139]$} & {$[-0.134]$} \\
\hline \multirow{3}{*}{$\begin{array}{l}\text { Participation More than } 2 \text { Years } \times \\
\text { After Welfare Reform }\end{array}$} & -0.116 & -0.167 & -0.140 & -0.181 \\
\hline & $(0.025)$ & $(0.104)$ & $(0.044)$ & $(0.180)$ \\
\hline & {$[-0.155]$} & {$[-0.305]$} & {$[-0.174]$} & {$[-0.332]$} \\
\hline Instrumental Variables & No & Yes & No & Yes \\
\hline Misclassification Correction & No & No & Yes & Yes \\
\hline Weak IV Test Statistic & & 26.671 & & 26.652 \\
\hline p-value (Weak IV) & & 0.372 & & 0.373 \\
\hline Hansen J Statistic & & 17.150 & & 16.543 \\
\hline \multirow[t]{2}{*}{ p-value (J Statistic) } & & 0.842 & & 0.868 \\
\hline & \multicolumn{4}{|c|}{ Mother's Participation, At Most 2 Years } \\
\hline Percent Change in Levels & $-56 \%$ & $-46 \%$ & $-38 \%$ & $38 \%$ \\
\hline \multirow[t]{2}{*}{ Percent Change over Baseline } & $-23 \%$ & $-6 \%$ & $-13 \%$ & $92 \%$ \\
\hline & \multicolumn{4}{|c|}{ Mother's Participation, More than 2 Years } \\
\hline Percent Change in Levels & $-59 \%$ & $-60 \%$ & $-44 \%$ & $-44 \%$ \\
\hline Percent Change over Baseline & $-29 \%$ & $-29 \%$ & $-22 \%$ & $-22 \%$ \\
\hline Number of Daughters & 2961 & 2961 & 2961 & 2961 \\
\hline Observations & 56067 & 56067 & 56067 & 56067 \\
\hline \multicolumn{5}{|c|}{$\begin{array}{l}\text { Notes: Weighted estimates are shown with unweighted versions of point estimates below in brackets. Robust standard } \\
\text { errors with state clustering are shown in parentheses. All specifications control for state and year effects in addition to } \\
\text { time-varying controls for daughter's age, age squared, and indicators for number of children equal to } 1,2,3 \text {, or at least } \\
\text { 4. Instrumental variables include the average and maximum of mother's AFDC/TANF benefit standard and } \\
\text { federal/state EITC by family size during the critical exposure period of daughter's ages } 12-18 \text {, interactions of each with } \\
\text { an indicator for welfare reform, and interactions between each mother IV and between each reform-mother IV. The } \\
\text { weak IV test statistic is a Kleibergen-Paap (2006) rank statistic. }\end{array}$} \\
\hline
\end{tabular}


TABLE 8. HETEROGENEOUS INTERGENERATIONAL TRANSMISSION OF AFDC/TANF PARTICIPATION

\begin{tabular}{|c|c|c|c|c|c|c|}
\hline \multirow[t]{2}{*}{ TRANSMISSION EFFECTS BY: } & \multicolumn{3}{|c|}{ RACE } & \multicolumn{3}{|c|}{ STATE REFORM AGGRESSIVENESS } \\
\hline & (1) & (2) & (3) & (4) & (5) & (6) \\
\hline & \multicolumn{3}{|c|}{ Black } & \multicolumn{3}{|c|}{ Aggressive States } \\
\hline \multirow[t]{3}{*}{ Mother's Participation } & 0.166 & 0.059 & 0.408 & 0.139 & 0.098 & 0.153 \\
\hline & $(0.027)$ & $(0.040)$ & $(0.166)$ & $(0.016)$ & $(0.031)$ & $(0.035)$ \\
\hline & {$[0.192]$} & {$[0.120]$} & [0.849] & [0.174] & [0.112] & {$[0.211]$} \\
\hline \multirow{3}{*}{$\begin{array}{c}\text { Mother's Participation } \times \\
\text { After Welfare Reform }\end{array}$} & -0.101 & -0.190 & -0.181 & -0.100 & -0.128 & -0.118 \\
\hline & $(0.032)$ & $(0.035)$ & $(0.186)$ & $(0.022)$ & $(0.014)$ & $(0.032)$ \\
\hline & {$[-0.156]$} & {$[-0.187]$} & {$[-0.703]$} & {$[-0.144]$} & [-0.148] & {$[-0.174]$} \\
\hline & \multicolumn{3}{|c|}{ White } & \multicolumn{3}{|c|}{ Non-Aggressive States } \\
\hline \multirow[t]{3}{*}{ Mother's Participation } & 0.068 & 0.030 & 0.089 & 0.148 & 0.071 & 0.256 \\
\hline & $(0.013)$ & $(0.033)$ & $(0.057)$ & $(0.018)$ & $(0.032)$ & $(0.075)$ \\
\hline & [0.086] & {$[0.053]$} & {$[0.166]$} & {$[0.217]$} & [0.123] & [0.449] \\
\hline \multirow{3}{*}{$\begin{array}{c}\text { Mother's Participation } \times \\
\text { After Welfare Reform }\end{array}$} & -0.057 & -0.044 & -0.081 & -0.101 & -0.127 & -0.186 \\
\hline & $(0.014)$ & $(0.022)$ & $(0.059)$ & $(0.018)$ & $(0.024)$ & $(0.063)$ \\
\hline & {$[-0.081]$} & {$[-0.040]$} & {$[-0.243]$} & [-0.169] & [-0.169] & {$[-0.341]$} \\
\hline Daughter Fixed Effects & No & Yes & No & No & Yes & No \\
\hline Instrumental Variables & No & No & Yes & No & No & Yes \\
\hline Weak IV Test Statistic & & & 23.240 & & & 27.817 \\
\hline p-value (Weak IV) & & & 0.039 & & & 0.010 \\
\hline Hansen J Statistic & & & 11.358 & & & 8.856 \\
\hline \multirow[t]{2}{*}{ p-value (J Statistic) } & & & 0.498 & & & 0.715 \\
\hline & \multicolumn{3}{|c|}{ Black } & \multicolumn{3}{|c|}{ Aggressive } \\
\hline Percent Change in Levels & $-61 \%$ & $-100 \%$ & $-44 \%$ & $-72 \%$ & $-100 \%$ & $-77 \%$ \\
\hline \multirow[t]{2}{*}{ Percent Change over Baseline } & $-31 \%$ & - & $-2 \%$ & $-51 \%$ & - & $-60 \%$ \\
\hline & \multicolumn{3}{|c|}{ White } & \multicolumn{3}{|c|}{ Non-Aggressive } \\
\hline Percent Change in Levels & $-84 \%$ & $-100 \%$ & $-91 \%$ & $-68 \%$ & $-100 \%$ & $-73 \%$ \\
\hline Percent Change over Baseline & $-72 \%$ & - & $-84 \%$ & $-44 \%$ & - & $-52 \%$ \\
\hline Number of Daughters & 2849 & 2849 & 2849 & 2961 & 2961 & 2961 \\
\hline Observations & 54963 & 54963 & 54963 & 56067 & 56067 & 56067 \\
\hline \multicolumn{7}{|c|}{$\begin{array}{l}\text { Notes: Weighted estimates are shown with unweighted versions of point estimates below in brackets. Robust standard } \\
\text { errors with state clustering are shown in parentheses. All specifications control for state and year effects in addition to } \\
\text { time-varying controls for daughter's age, age squared, and indicators for number of children equal to 1,2, 3, or at least } \\
\text { 4. Instrumental variables used in each specification include the average and maximum of mother's AFDC/TANF } \\
\text { benefit standard and federal/state EITC by family size during the critical exposure period of daughter's ages 12-18, } \\
\text { interactions of each with an indicator for welfare reform, and all interacted with an indicator for daughter's race is black } \\
\text { in the top panel or an indicator for aggressive welfare reform in the bottom panel. The weak IV test statistic is a } \\
\text { Kleibergen-Paap (2006) rank statistic. }\end{array}$} \\
\hline
\end{tabular}


TABLE 9. INTERGENERATIONAL TRANSMISSION OF AFDC/TANF, FOOD STAMPS/SNAP, AND SUPPLEMENTAL SECURITY INCOME PARTICIPATION

\begin{tabular}{|c|c|c|c|c|}
\hline & (1) & (2) & (3) & (4) \\
\hline \multicolumn{5}{|c|}{ A. Effect of Mother's AFDC/TANF on Daughter's AFDC/TANF, SNAP, SSI } \\
\hline Mother's Participation & $\begin{array}{c}0.226 \\
(0.019) \\
{[0.270]}\end{array}$ & $\begin{array}{c}0.215 \\
(0.068) \\
{[0.407]}\end{array}$ & $\begin{array}{c}0.293 \\
(0.024) \\
{[0.346]}\end{array}$ & $\begin{array}{c}0.259 \\
(0.089) \\
{[0.504]}\end{array}$ \\
\hline After Welfare Reform & $\begin{array}{c}0.002 \\
(0.013) \\
{[0.020]}\end{array}$ & $\begin{array}{l}-0.033 \\
(0.030) \\
{[0.026]}\end{array}$ & $\begin{array}{r}-0.011 \\
(0.020) \\
{[-0.007]}\end{array}$ & $\begin{array}{r}-0.072 \\
(0.042) \\
{[-0.026]}\end{array}$ \\
\hline $\begin{array}{c}\text { Mother's Participation } \times \\
\text { After Welfare Reform }\end{array}$ & $\begin{array}{c}-0.044 \\
(0.021) \\
{[-0.052]}\end{array}$ & $\begin{array}{c}0.099 \\
(0.077) \\
{[-0.027]}\end{array}$ & $\begin{array}{r}-0.020 \\
(0.030) \\
{[-0.013]}\end{array}$ & $\begin{array}{c}0.217 \\
(0.106) \\
{[0.080]}\end{array}$ \\
\hline $\begin{array}{l}\text { Instrumental Variables } \\
\text { Misclassification Correction }\end{array}$ & $\begin{array}{l}\text { No } \\
\text { No }\end{array}$ & $\begin{array}{l}\text { Yes } \\
\text { No }\end{array}$ & $\begin{array}{l}\text { No } \\
\text { Yes }\end{array}$ & $\begin{array}{l}\text { Yes } \\
\text { Yes }\end{array}$ \\
\hline $\begin{array}{l}\text { Weak IV Test Statistic } \\
\text { p-value (Weak IV) } \\
\text { Hansen J Statistic } \\
\text { p-value (J Statistic) }\end{array}$ & & $\begin{array}{r}23.157 \\
0.002 \\
10.657 \\
0.100\end{array}$ & & $\begin{array}{r}21.646 \\
0.003 \\
10.078 \\
0.121\end{array}$ \\
\hline $\begin{array}{l}\text { Percent Change in Levels } \\
\text { Percent Change over Baseline }\end{array}$ & $\begin{array}{l}-19 \% \\
42 \%\end{array}$ & $\begin{array}{l}46 \% \\
157 \%\end{array}$ & $\begin{array}{l}-7 \% \\
30 \%\end{array}$ & $\begin{array}{c}84 \% \\
156 \%\end{array}$ \\
\hline \multicolumn{5}{|c|}{ B. Effect of Mother's AFDC/TANF, SNAP, SSI on Daughter's AFDC/TANF, SNAP, SSI } \\
\hline Mother's Participation & $\begin{array}{c}0.160 \\
(0.012) \\
{[0.211]}\end{array}$ & $\begin{array}{c}0.161 \\
(0.048) \\
{[0.418]}\end{array}$ & $\begin{array}{c}0.207 \\
(0.016) \\
{[0.267]}\end{array}$ & $\begin{array}{c}0.179 \\
(0.062) \\
{[0.505]}\end{array}$ \\
\hline After Welfare Reform & $\begin{array}{l}-0.009 \\
(0.014) \\
{[0.002]}\end{array}$ & $\begin{array}{r}-0.075 \\
(0.033) \\
{[-0.020]}\end{array}$ & $\begin{array}{r}-0.031 \\
(0.022) \\
{[-0.038]}\end{array}$ & $\begin{array}{c}-0.152 \\
(0.047) \\
{[-0.114]}\end{array}$ \\
\hline $\begin{array}{c}\text { Mother's Participation } \times \\
\text { After Welfare Reform }\end{array}$ & $\begin{array}{r}-0.014 \\
(0.015) \\
{[-0.027]}\end{array}$ & $\begin{array}{c}0.151 \\
(0.058) \\
{[0.048]}\end{array}$ & $\begin{array}{c}0.014 \\
(0.022) \\
{[0.017]}\end{array}$ & $\begin{array}{c}0.307 \\
(0.081) \\
{[0.192]}\end{array}$ \\
\hline $\begin{array}{l}\text { Instrumental Variables } \\
\text { Misclassification Correction }\end{array}$ & $\begin{array}{l}\text { No } \\
\text { No }\end{array}$ & $\begin{array}{l}\text { Yes } \\
\text { No }\end{array}$ & $\begin{array}{l}\text { No } \\
\text { Yes }\end{array}$ & $\begin{array}{l}\text { Yes } \\
\text { Yes }\end{array}$ \\
\hline $\begin{array}{l}\text { Weak IV Test Statistic } \\
\text { p-value (Weak IV) } \\
\text { Hansen J Statistic } \\
\text { p-value (J Statistic) }\end{array}$ & & $\begin{array}{r}19.487 \\
0.192 \\
15.938 \\
0.317\end{array}$ & & $\begin{array}{r}16.439 \\
0.126 \\
11.638 \\
0.310\end{array}$ \\
\hline $\begin{array}{l}\text { Percent Change in Levels } \\
\text { Percent Change over Baseline }\end{array}$ & $\begin{array}{l}-9 \% \\
61 \%\end{array}$ & $\begin{array}{l}94 \% \\
241 \%\end{array}$ & $\begin{array}{l}7 \% \\
49 \%\end{array}$ & $\begin{array}{l}172 \% \\
278 \%\end{array}$ \\
\hline $\begin{array}{l}\text { Number of Daughters } \\
\text { Observations }\end{array}$ & $\begin{array}{c}2961 \\
56067\end{array}$ & $\begin{array}{c}2961 \\
56067\end{array}$ & $\begin{array}{c}2961 \\
56067\end{array}$ & $\begin{array}{c}2961 \\
56067\end{array}$ \\
\hline \multicolumn{5}{|c|}{$\begin{array}{l}\text { Notes: Weighted estimates are shown with unweighted versions of point estimates below in brackets. Robust standard } \\
\text { errors with state clustering are shown in parentheses. All specifications control for state and year effects in addition to } \\
\text { time-varying controls for daughter's age, age squared, and indicators for number of children equal to 1, 2, 3, or at least } \\
\text { 4. Instrumental variables include the average and maximum of mother's AFDC/TANF benefit standard and } \\
\text { federal/state EITC (as well as Food Stamps/SNAP maximum value for Panel B) by family size during the critical } \\
\text { exposure period of daughter's ages 12-18, and interactions of each with an indicator for welfare reform. The weak IV } \\
\text { test statistic is a Kleibergen-Paap (2006) rank statistic. Abbreviations: Food Stamps/Supplemental Nutrition Assistance } \\
\text { Program (SNAP) and Supplemental Security Income (SSI). }\end{array}$} \\
\hline
\end{tabular}




\section{Appendix A. Notes on Misclassification Bias Corrections}

Estimates based on equation (1) rely on self-reported data for a daughter's welfare participation at time $t$ and her mother's self-reported participation at any time prior to $t$,

$$
W_{i s t}^{d}=\alpha+\beta^{\prime} x_{i s t}^{d}+\delta W_{i s, \forall j<t}^{m}+\gamma R_{s t}^{m}+\theta R_{s t}^{m} W_{i s, \forall j<t}^{m}+\mu_{s}^{d}+\rho_{t}^{d}+v_{i s t}^{d} \text {, }
$$

where $W_{i s, \forall j<t}^{m}=\max \left\{W_{i s, t-1}^{m}, W_{i s, t-2}^{m}, W_{i s, t-3}^{m}, \ldots\right\}$. Let the true participation status be denoted $\widetilde{W}_{i s t}^{d}$ for daughter at time $t, \widetilde{W}_{i s t}^{m}$ for mother at time $t$, and $\widetilde{W}_{i s, \forall j<t}^{m}$ for mother at any time prior to time $t$. In principle, both $W_{i s t}^{d}$ and $W_{i s t}^{m}$ can be affected by misclassification error. However, as demonstrated below, $W_{i s, \forall j<t}^{m}$ does not represent a challenge for point estimation as long as individuals have some positive probability of truthfully reporting welfare participation at time $t$.

To fix ideas, consider for simplicity $t=3$ with $j \in\{1,2\}$ and let the probability of truthfully reporting participation be defined as $q=\mathrm{P}\left(W_{i s t}^{m}=1 \mid \widetilde{W}_{i s t}^{m}=1\right)>0$. In this case, the mother's measure of any prior participation at $t=3$ will be accurately reported with probability

$$
\begin{aligned}
\mathrm{P}\left(W_{i s, \forall j<3}^{m}=\right. & \left.1 \mid \widetilde{W}_{i s, \forall j<3}^{m}=1\right)= \\
& \mathrm{P}\left(W_{i s 1}^{m}=1 \mid \widetilde{W}_{i s 1}^{m}=1\right)+\mathrm{P}\left(W_{i s 2}^{m}=1 \mid \widetilde{W}_{i s 2}^{m}=1\right) \\
& -\mathrm{P}\left(W_{i s 1}^{m}=1 \mid \widetilde{W}_{i s 1}^{m}=1\right) \mathrm{P}\left(W_{i s 2}^{m}=1 \mid \widetilde{W}_{i s 2}^{m}=1, W_{i s 1}^{m}=1, \widetilde{W}_{i s 1}^{m}=1\right) .
\end{aligned}
$$

Denoting $\mathrm{P}\left(W_{i s 2}^{m}=1 \mid \widetilde{W}_{i s 2}^{m}=1, W_{i s 1}^{m}=1, \widetilde{W}_{i s 1}^{m}=1\right)=r$, it follows that,

$$
\mathrm{P}\left(W_{i s, \forall j<3}^{m}=1 \mid \widetilde{W}_{i s, \forall j<3}^{m}=1\right)=q(2-r)>q=\mathrm{P}\left(W_{i s 3}^{m}=1 \mid \widetilde{W}_{i s 3}^{m}=1\right) .
$$

We can now generalize the argument assuming, again for simplicity in exposition, that $q=r$. The probability of ever truthfully reported welfare participation under the above conditions can 
be expressed (based on the inclusion-exclusion principle for the union of finite events (Billingsley 1995, p. 24)) as

$Q_{t}(q) \equiv \mathrm{P}\left(W_{i s, \forall j<t}^{m}=1 \mid \widetilde{W}_{i s, \forall j<t}^{m}=1\right)=\sum_{j=1}^{t-1}(-1)^{j-1}\left(\begin{array}{c}t-1 \\ j\end{array}\right) q^{j}$, where $\left(\begin{array}{c}t-1 \\ j\end{array}\right)=\frac{(t-1) !}{j !(t-1-j) !}$

which is increasing in the number of time periods observed. For our analysis, the mother's minimum number of time periods is five years, and for the average reporting rate for 1970-2000 (see Table A1 and Meyer et al. 2015b), the probability is $Q_{5}(q=0.668) \approx 0.996$, or for the minimum reporting rate over that time period, $Q_{5}(q=0.318) \approx 0.852$. Given that mothers are observed for about 14 years on average prior to the daughter's participation decision, the probability that a mother truthfully reports any prior participation tends to 1 , as shown in the graph below.

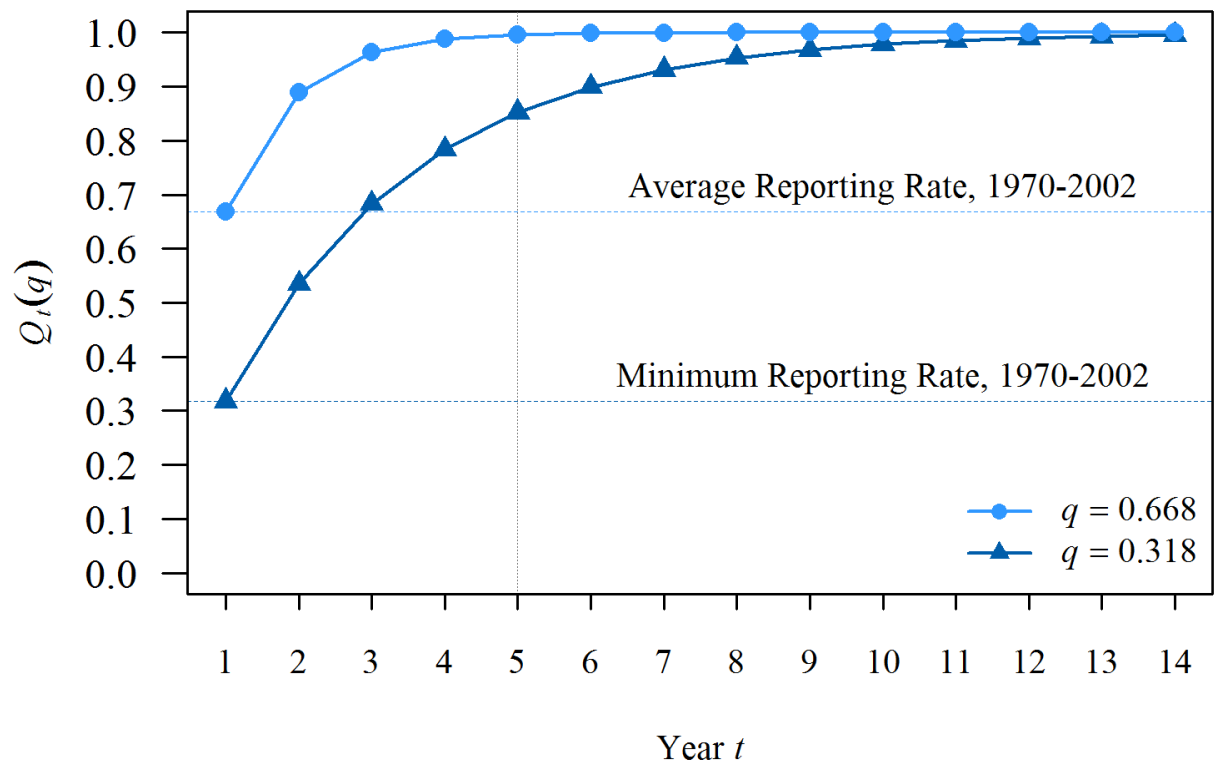


We focus instead on misclassification in the binary dependent variable for daughter's current welfare status. The probability that a daughter reports participating in welfare can be written as

$$
\mathrm{P}\left(W_{i s t}^{d}=1\right)=\mathrm{P}\left(W_{i s t}^{d}=1 \mid \widetilde{W}_{i s t}^{d}=1\right) \mathrm{P}\left(\widetilde{W}_{i s t}^{d}=1\right)+\mathrm{P}\left(W_{i s t}^{d}=1 \mid \widetilde{W}_{i s t}^{d}=0\right) \mathrm{P}\left(\widetilde{W}_{i s t}^{d}=0\right),
$$

where false negatives are defined as $\tau_{1, i s t}:=\mathrm{P}\left(W_{i s t}^{d}=0 \mid \widetilde{W}_{i s t}^{d}=1\right)$ and false positives are defined as $\tau_{0, i s t}:=\mathrm{P}\left(W_{i s t}^{d}=1 \mid \widetilde{W}_{i s t}^{d}=0\right)=0$ by assumption. ${ }^{26}$ This assumption is standard in the literature as false positive reports are relatively small, and these misreports typically correspond to individuals who mistake the source or timing of actual welfare participation. Therefore, using equation (1) and $\tau_{1, i s t}$, we can rewrite the daughter's probability of reported welfare participation as

$$
\mathrm{P}\left(W_{i s t}^{d}=1\right)=\left[1-\tau_{1, i s t}\right]\left[\alpha+\beta^{\prime} \boldsymbol{x}_{i s t}^{d}+\delta W_{i s, \forall j<t}^{m}+\gamma R_{s t}^{m}+\theta R_{s t}^{m} W_{i s, \forall j<t}^{m}+\mu_{s}^{d}+\rho_{t}^{d}+v_{i s t}^{d}\right] .
$$

We estimate the previous equation in two steps. The first step estimates misclassification probabilities based on estimates of AFDC/TANF reporting rates in the PSID by Meyer, Mok, and Sullivan (2015b) considering that $\mathrm{E}\left(\tau_{1, i s t}\right)=\tau_{1 t}$. Table A1 shows the reporting rates used in estimation. In the second stage, we estimate the parameter of interest, $(\delta, \gamma, \theta)$, by estimating the model of $W_{i s t}^{d}$ on weighted independent variables including a weighted intercept $\left[1-\hat{\tau}_{1 t}\right] \alpha$, $\left[1-\hat{\tau}_{1 t}\right] \mu_{s}^{d}$ and $\left[1-\hat{\tau}_{1 t}\right] \rho_{t}^{d}$.

\footnotetext{
${ }^{26}$ Note that whereas $q$ is assumed fixed for the purposes of exposition above, false negatives here can be shown equivalently as $\tau_{1, i s t}=1-q_{i s t}$.
} 
TABLE A1. PSID REPORTING RATES TAKEN AS GIVEN FOR MISCLASSIFICATION BIAS CORRECTION ESTIMATES

\begin{tabular}{|c|c|c|c|c|c|c|}
\hline \multirow[b]{3}{*}{ Year } & \multicolumn{3}{|c|}{ AFDC/TANF } & \multicolumn{3}{|c|}{ Food Stamps/SNAP } \\
\hline & \multicolumn{2}{|c|}{ Meyer, et al. (2015b) } & \multirow{2}{*}{$\begin{array}{l}\text { Estimation } \\
\text { Parameter }\end{array}$} & \multicolumn{2}{|c|}{ Meyer, et al. (2015b) } & \multirow{2}{*}{$\begin{array}{l}\text { Estimation } \\
\text { Parameter }\end{array}$} \\
\hline & Transfers & Cases & & Transfers & Cases & \\
\hline 1975 & 0.646 & & 0.722 & 0.779 & & 0.773 \\
\hline 1976 & 0.662 & & 0.740 & 0.734 & & 0.728 \\
\hline 1977 & 0.630 & & 0.704 & 0.754 & & 0.748 \\
\hline 1978 & 0.661 & & 0.739 & 0.772 & & 0.766 \\
\hline 1979 & 0.642 & & 0.717 & 0.782 & & 0.776 \\
\hline 1980 & 0.700 & & 0.782 & 0.761 & 0.782 & 0.755 \\
\hline 1981 & 0.699 & & 0.781 & 0.761 & 0.780 & 0.755 \\
\hline 1982 & 0.679 & & 0.759 & 0.832 & 0.841 & 0.826 \\
\hline 1983 & 0.708 & & 0.791 & 0.808 & 0.817 & 0.802 \\
\hline 1984 & 0.631 & & 0.705 & 0.830 & 0.784 & 0.824 \\
\hline 1985 & 0.594 & & 0.664 & 0.817 & 0.786 & 0.811 \\
\hline 1986 & 0.587 & & 0.656 & 0.818 & 0.841 & 0.812 \\
\hline 1987 & 0.555 & & 0.620 & 0.871 & 0.846 & 0.864 \\
\hline 1988 & 0.620 & & 0.693 & 0.862 & 0.847 & 0.855 \\
\hline 1989 & 0.576 & & 0.644 & 0.982 & 0.845 & 0.974 \\
\hline 1990 & 0.586 & & 0.655 & 0.857 & 0.770 & 0.850 \\
\hline 1991 & 0.612 & & 0.684 & 0.756 & 0.681 & 0.750 \\
\hline 1992 & 0.600 & & 0.671 & 0.731 & 0.720 & 0.725 \\
\hline 1993 & 0.528 & 0.605 & 0.590 & 0.621 & 0.700 & 0.616 \\
\hline 1994 & 0.474 & 0.569 & 0.530 & 0.662 & 0.686 & 0.657 \\
\hline 1995 & 0.493 & 0.539 & 0.551 & 0.632 & 0.652 & 0.627 \\
\hline 1996 & 0.541 & 0.572 & 0.605 & 0.572 & 0.604 & 0.568 \\
\hline 1997 & & & 0.508 & 0.509 & 0.522 & 0.505 \\
\hline 1998 & 0.369 & 0.403 & 0.412 & 0.563 & 0.561 & 0.559 \\
\hline 1999 & & & 0.387 & 0.654 & 0.535 & 0.649 \\
\hline 2000 & 0.323 & 0.445 & 0.361 & 0.617 & 0.583 & 0.612 \\
\hline 2001 & & & 0.350 & 0.592 & 0.573 & 0.587 \\
\hline 2002 & 0.303 & 0.343 & 0.339 & 0.744 & 0.595 & 0.738 \\
\hline 2003 & 0.387 & 0.458 & 0.432 & 0.685 & 0.719 & 0.680 \\
\hline 2004 & 0.487 & 0.510 & 0.544 & 0.718 & 0.807 & 0.712 \\
\hline 2005 & 0.285 & 0.285 & 0.318 & 0.688 & 0.635 & 0.683 \\
\hline 2006 & 0.395 & 0.365 & 0.441 & 0.693 & 0.758 & 0.688 \\
\hline 2007 & & & 0.472 & 0.742 & 0.794 & 0.736 \\
\hline 2008 & 0.450 & 0.497 & 0.503 & 0.777 & 0.791 & 0.771 \\
\hline 2009 & & & 0.486 & 0.704 & 0.764 & 0.699 \\
\hline 2010 & 0.419 & 0.504 & 0.468 & 0.648 & 0.713 & 0.643 \\
\hline 2011 & & & 0.477 & & & 0.671 \\
\hline 2012 & & & 0.473 & & & 0.657 \\
\hline $\begin{array}{l}\text { Notes: PS } \\
\text { stamps/S } \\
\text { correction } \\
\text { transfers i } \\
\text { with avail } \\
\text { where we } \\
\text { two-year }\end{array}$ & $\begin{array}{l}\text { rting rates } \mathrm{f} \\
\text { estimated } \\
\text { es, }\left(1-\hat{\tau}_{1}\right. \\
\text { st column i } \\
\text { a, which is } \\
\text { sing both ra } \\
\text { average for }\end{array}$ & $\begin{array}{l}\text { ar amou } \\
\text { er, et al. } \\
\text { he imput } \\
\text { by the } \\
\text { imately } \\
\text { amount } \\
\text { t years. }\end{array}$ & $\begin{array}{l}\text { ansfers and } n \\
\text { b). The estim } \\
\text { orting rate. Tl } \\
\text { e ratio of the } \\
\text { for AFDC/T } \\
\text { ases, we line }\end{array}$ & $\begin{array}{l}\mathrm{r} \text { of cases } \mathrm{fo} \\
\text { parameter u } \\
\text { puted rate is } \\
\text { ing rates for } \\
\text { nd } 0.992 \mathrm{fo} \\
\text { terpolate b }\end{array}$ & $\begin{array}{l}\text { DC/TANH } \\
\text { misclass } \\
\text { to the re } \\
\text { fers and c } \\
\text { stamps/s } \\
\text { observe }\end{array}$ & $\begin{array}{l}\text { food } \\
\text { lon bias } \\
\text { g rate for } \\
\text { given the years } \\
\text {. In years } \\
\text { rs and use a }\end{array}$ \\
\hline
\end{tabular}




\section{Appendix B. Additional Results and Robustness Checks}

As referenced throughout the paper, the following section introduces various tables with additional results that explore the sensitivity of our main findings. The qualitative results of welfare reform are consistent: there is a causal influence from mother's welfare participation, and reform attenuates this transmission by more than 50 percent in levels and more than 30 percent above baseline probabilities given the mechanical change in participation after reform.

In Table B1, we compare estimates for different sets of instrumental variables, which are key to identifying the effect of mother's participation given her selection into welfare. Then, in Table B2 we re-estimate the baseline IV model including mother's variables related to her lifetime earnings ability: log of average family income, educational attainment in years, and both income and education (measured when the daughter is aged 12-18). Next, we re-estimate the baseline specifications from Table 2 for only the Survey Research Center (SRC) subsample of the PSID in Table B3. This PSID subsample is nationally representative without the oversampling of low-income and minority families in the Survey of Economic Opportunity (SEO) subsample. Lastly, in Table B4 we re-estimate the baseline results in Table 2 for a sample of eldest daughters only. Eldest daughters have the most opportunity to continue learning from their mothers' participation after leaving home since there may still be younger siblings living with the mother, and this sample abstracts away from larger families being overrepresented in the data. 
TABLE B1. INTERGENERATIONAL TRANSMISSION OF AFDC/TANF PARTICIPATION WITH ALTERNATIVE INSTRUMENTAL VARIABLES

\begin{tabular}{|c|c|c|c|c|c|c|}
\hline & (1) & (2) & (3) & (4) & $(5)$ & (6) \\
\hline \multirow[t]{3}{*}{ Mother's Participation } & 0.213 & 0.278 & 0.279 & 0.322 & 0.419 & 0.426 \\
\hline & $(0.052)$ & $(0.056)$ & $(0.056)$ & $(0.087)$ & $(0.087)$ & $(0.088)$ \\
\hline & [0.339] & {$[0.371]$} & {$[0.379]$} & {$[0.534]$} & {$[0.569]$} & {$[0.581]$} \\
\hline \multirow[t]{3}{*}{ After Welfare Reform } & 0.048 & 0.073 & 0.074 & 0.051 & 0.087 & 0.091 \\
\hline & $(0.016)$ & $(0.016)$ & $(0.017)$ & $(0.027)$ & $(0.022)$ & $(0.024)$ \\
\hline & [0.119] & {$[0.138]$} & {$[0.146]$} & [0.139] & {$[0.156]$} & {$[0.168]$} \\
\hline \multirow{3}{*}{$\begin{array}{c}\text { Mother's Participation } \times \\
\text { After Welfare Reform }\end{array}$} & -0.125 & -0.201 & -0.204 & -0.122 & -0.236 & -0.251 \\
\hline & $(0.043)$ & $(0.041)$ & $(0.045)$ & $(0.074)$ & $(0.056)$ & $(0.064)$ \\
\hline & {$[-0.218]$} & {$[-0.254]$} & {$[-0.271]$} & {$[-0.265]$} & {$[-0.297]$} & {$[-0.323]$} \\
\hline Misclassification Correction & No & No & No & Yes & Yes & Yes \\
\hline \multicolumn{7}{|l|}{ Instrumental Variables: } \\
\hline \multirow{3}{*}{$\begin{array}{l}\text { AFDC/TANF } \\
\text { EITC } \\
\text { Unemployment }\end{array}$} & \multirow[t]{3}{*}{$\mathrm{X}$} & \multirow[t]{2}{*}{$\mathrm{X}$} & $\mathrm{X}$ & \multirow[t]{3}{*}{$\mathrm{X}$} & \multirow[t]{2}{*}{$\mathrm{X}$} & $\mathrm{X}$ \\
\hline & & & $\mathrm{X}$ & & & $\mathrm{X}$ \\
\hline & & $\mathrm{X}$ & $X$ & & $\mathrm{X}$ & $\mathrm{X}$ \\
\hline Weak IV Test Statistic & 22.275 & 25.949 & 26.560 & 20.349 & 25.285 & 25.941 \\
\hline p-value (Weak IV) & 0.000 & 0.001 & 0.005 & 0.000 & 0.001 & 0.007 \\
\hline Hansen J Statistic & 1.175 & 3.748 & 4.083 & 0.995 & 3.872 & 4.692 \\
\hline p-value (J Statistic) & 0.556 & 0.711 & 0.944 & 0.608 & 0.694 & 0.911 \\
\hline Percent Change in Levels & $-59 \%$ & $-72 \%$ & $-73 \%$ & $-38 \%$ & $-56 \%$ & $-59 \%$ \\
\hline Percent Change over Baseline & $-27 \%$ & $-51 \%$ & $-53 \%$ & $-13 \%$ & $-39 \%$ & $-43 \%$ \\
\hline Number of Daughters & 2961 & 2961 & 2961 & 2961 & 2961 & 2961 \\
\hline Observations & 56067 & 56067 & 56067 & 56067 & 56067 & 56067 \\
\hline \multicolumn{7}{|c|}{$\begin{array}{l}\text { Notes: Weighted estimates are shown with unweighted versions of point estimates below in brackets. Robust standard } \\
\text { errors with state clustering are shown in parentheses. All specifications control for state, and year effects in addition to } \\
\text { time-varying controls for daughter's age, age squared, and indicators for number of children equal to } 1,2,3 \text {, or at least } \\
4 \text {, and for mother's log of mean income and mean educational attainment for prior years. Instrumental variables include } \\
\text { both the average and maximum of each variable listed above, along with interactions of each with an indicator for } \\
\text { welfare reform, measured during the critical exposure period of daughter's ages } 12-18 \text {. The weak IV test statistic is a } \\
\text { Kleibergen-Paap (2006) rank statistic. }\end{array}$} \\
\hline
\end{tabular}


TABLE B2. IV ESTIMATES OF INTERGENERATIONAL TRANSMISSION OF AFDC/TANF PARTICIPATION WITH CONTROLS FOR MOTHER'S CHARACTERISTICS

\begin{tabular}{|c|c|c|c|c|c|c|}
\hline & (1) & (2) & (3) & (4) & (5) & (6) \\
\hline \multirow[t]{3}{*}{ Mother's Participation } & 0.242 & 0.232 & 0.242 & 0.374 & 0.337 & 0.367 \\
\hline & $(0.050)$ & $(0.055)$ & $(0.057)$ & $(0.077)$ & $(0.087)$ & $(0.089)$ \\
\hline & {$[0.352]$} & {$[0.421]$} & [0.393] & {$[0.532]$} & {$[0.640]$} & {$[0.590]$} \\
\hline \multirow[t]{3}{*}{ After Welfare Reform } & 0.058 & 0.058 & 0.058 & 0.069 & 0.065 & 0.069 \\
\hline & $(0.016)$ & $(0.016)$ & $(0.016)$ & $(0.025)$ & $(0.023)$ & $(0.025)$ \\
\hline & {$[0.125]$} & [0.139] & [0.127] & [0.141] & {$[0.157]$} & {$[0.142]$} \\
\hline \multirow{3}{*}{$\begin{array}{c}\text { Mother's Participation } \times \\
\text { After Welfare Reform }\end{array}$} & -0.156 & -0.159 & -0.160 & -0.179 & -0.174 & -0.184 \\
\hline & $(0.041)$ & $(0.042)$ & $(0.044)$ & $(0.067)$ & $(0.064)$ & $(0.070)$ \\
\hline & {$[-0.231]$} & {$[-0.258]$} & {$[-0.235]$} & {$[-0.269]$} & {$[-0.304]$} & {$[-0.273]$} \\
\hline Misclassification Correction & No & No & No & Yes & Yes & Yes \\
\hline \multicolumn{7}{|c|}{ Mother Controls Averaged over Daughter's Critical Exposure Years: } \\
\hline Educational Attainment & Yes & No & Yes & Yes & No & Yes \\
\hline Log Family Income & No & Yes & Yes & No & Yes & Yes \\
\hline Weak IV Test Statistic & 22.794 & 22.329 & 23.621 & 23.447 & 21.052 & 23.661 \\
\hline p-value (Weak IV) & 0.002 & 0.002 & 0.001 & 0.001 & 0.004 & 0.001 \\
\hline Hansen J Statistic & 2.267 & 2.485 & 2.429 & 2.323 & 2.353 & 2.481 \\
\hline p-value (J Statistic) & 0.894 & 0.870 & 0.876 & 0.888 & 0.885 & 0.871 \\
\hline Percent Change in Levels & $-64 \%$ & $-69 \%$ & $-66 \%$ & $-48 \%$ & $-52 \%$ & $-50 \%$ \\
\hline Percent Change over Baseline & $-37 \%$ & $-45 \%$ & $-40 \%$ & $-27 \%$ & $-33 \%$ & $-31 \%$ \\
\hline Number of Daughters & 2946 & 2946 & 2946 & 2946 & 2946 & 2946 \\
\hline Observations & 55945 & 55945 & 55945 & 55945 & 55945 & 55945 \\
\hline $\begin{array}{l}\text { Notes: Weighted estimates are shov } \\
\text { errors with state clustering are shov } \\
\text { time-varying controls for daughter' } \\
\text { 4. Instrumental variables used in ea } \\
\text { benefit standard and federal/state E } \\
\text { interactions of each with an indicat } \\
\text { statistic. }\end{array}$ & $\begin{array}{l}\text { n with unw } \\
n \text { in parentl } \\
\text { age, age sc } \\
\text { h specifica } \\
\text { TC by fami } \\
r \text { for welfar }\end{array}$ & $\begin{array}{l}\text { hted version } \\
\text { es. All speci } \\
\text { red, and ind } \\
\text { n include the } \\
\text { size during t } \\
\text { eform. The }\end{array}$ & $\begin{array}{l}\text { f point esti } \\
\text { tions cont } \\
\text { ors for nur } \\
\text { erage and } \\
\text { critical exp }\end{array}$ & $\begin{array}{l}\text { tes below in } \\
\text { for state an } \\
\text { ximum of childre } \\
\text { ure period o }\end{array}$ & $\begin{array}{l}\text { rackets. Rob } \\
\text { ear effects in } \\
\text { qual to } 1,2 \text {, } \\
\text { her's AFDC } \\
\text { aughter's ag }\end{array}$ & $\begin{array}{l}\text { t standard } \\
\text { ddition to } \\
\text { or at least } \\
\text { ANF } \\
\text { 12-18, and } \\
\text { 06) rank }\end{array}$ \\
\hline
\end{tabular}


TABLE B3. INTERGENERATIONAL TRANSMISSION OF AFDC/TANF PARTICIPATION FOR THE SURVEY RESEARCH CENTER (SRC) SAMPLE ONLY

\begin{tabular}{|c|c|c|c|c|}
\hline & (1) & (2) & (3) & (4) \\
\hline \multirow[t]{3}{*}{ Mother's Participation } & 0.092 & 0.122 & 0.153 & 0.167 \\
\hline & $(0.018)$ & $(0.044)$ & $(0.032)$ & $(0.071)$ \\
\hline & [0.114] & [0.164] & [0.181] & [0.202] \\
\hline \multirow[t]{3}{*}{ After Welfare Reform } & 0.021 & 0.029 & 0.029 & 0.033 \\
\hline & $(0.008)$ & $(0.015)$ & $(0.016)$ & $(0.025)$ \\
\hline & [0.029] & [0.043] & [0.043] & [0.048] \\
\hline \multirow{3}{*}{$\begin{array}{c}\text { Mother's Participation } \times \\
\text { After Welfare Reform }\end{array}$} & -0.060 & -0.092 & -0.081 & -0.095 \\
\hline & $(0.019)$ & $(0.051)$ & $(0.036)$ & $(0.091)$ \\
\hline & {$[-0.089]$} & {$[-0.142]$} & {$[-0.121]$} & {$[-0.138]$} \\
\hline Instrumental Variables & No & Yes & No & Yes \\
\hline Misclassification Correction & No & No & Yes & Yes \\
\hline Weak IV Test Statistic & & 19.845 & & 17.338 \\
\hline p-value (Weak IV) & & 0.006 & & 0.015 \\
\hline Hansen J Statistic & & 5.766 & & 5.632 \\
\hline p-value (J Statistic) & & 0.450 & & 0.466 \\
\hline Percent Change in Levels & $-65 \%$ & $-75 \%$ & $-53 \%$ & $-57 \%$ \\
\hline Percent Change over Baseline & $-39 \%$ & $-57 \%$ & $-34 \%$ & $-40 \%$ \\
\hline Number of Daughters & 1422 & 1422 & 1422 & 1422 \\
\hline Observations & 28917 & 28917 & 28917 & 28917 \\
\hline \multicolumn{5}{|c|}{$\begin{array}{l}\text { Notes: Weighted estimates are shown with unweighted versions of point estimates below in brackets. Robust standard } \\
\text { errors with state clustering are shown in parentheses. All specifications control for state and year effects in addition to } \\
\text { time-varying controls for daughter's age, age squared, and indicators for number of children equal to } 1,2,3 \text {, or at least } \\
\text { 4. Instrumental variables include the average and maximum of mother's AFDC/TANF benefit standard and } \\
\text { federal/state EITC by family size during the critical exposure period of daughter's ages } 12-18 \text {, and interactions of each } \\
\text { with an indicator for welfare reform. The weak IV test statistic is a Kleibergen-Paap (2006) rank statistic. }\end{array}$} \\
\hline
\end{tabular}




\section{TABLE B4. INTERGENERATIONAL TRANSMISSION OF AFDC/TANF PARTICIPATION FOR THE SUBSAMPLE OF ELDEST DAUGHTERS}

\begin{tabular}{|c|c|c|c|c|}
\hline & (1) & (2) & (3) & (4) \\
\hline \multirow[t]{3}{*}{ Mother's Participation } & 0.137 & 0.220 & 0.219 & 0.306 \\
\hline & $(0.014)$ & $(0.078)$ & $(0.022)$ & $(0.135)$ \\
\hline & [0.197] & [0.364] & [0.301] & {$[0.548]$} \\
\hline \multirow[t]{3}{*}{ After Welfare Reform } & 0.031 & 0.049 & 0.037 & 0.045 \\
\hline & $(0.007)$ & $(0.023)$ & $(0.013)$ & $(0.037)$ \\
\hline & {$[0.071]$} & [0.134] & [0.081] & {$[0.152]$} \\
\hline \multirow{3}{*}{$\begin{array}{c}\text { Mother's Participation } \times \\
\text { After Welfare Reform }\end{array}$} & -0.099 & -0.150 & -0.135 & -0.144 \\
\hline & $(0.017)$ & $(0.066)$ & $(0.030)$ & $(0.113)$ \\
\hline & {$[-0.157]$} & {$[-0.274]$} & {$[-0.201]$} & {$[-0.324]$} \\
\hline Instrumental Variables & No & Yes & No & Yes \\
\hline Misclassification Correction & No & No & Yes & Yes \\
\hline Weak IV Test Statistic & & 21.298 & & 18.619 \\
\hline p-value (Weak IV) & & 0.003 & & 0.009 \\
\hline Hansen J Statistic & & 2.616 & & 2.672 \\
\hline p-value (J Statistic) & & 0.855 & & 0.849 \\
\hline Percent Change in Levels & $-72 \%$ & $-68 \%$ & $-62 \%$ & $-47 \%$ \\
\hline Percent Change over Baseline & $-51 \%$ & $-44 \%$ & $-47 \%$ & $-26 \%$ \\
\hline Number of Daughters & 1914 & 1914 & 1914 & 1914 \\
\hline Observations & 36287 & 36287 & 36287 & 36287 \\
\hline \multicolumn{5}{|c|}{$\begin{array}{l}\text { Notes: Weighted estimates are shown with unweighted versions of point estimates below in brackets. Robust standard } \\
\text { errors with state clustering are shown in parentheses. All specifications control for state and year effects in addition to } \\
\text { time-varying controls for daughter's age, age squared, and indicators for number of children equal to } 1,2,3 \text {, or at least } \\
\text { 4. Instrumental variables include the average and maximum of mother's AFDC/TANF benefit standard and } \\
\text { federal/state EITC by family size during the critical exposure period of daughter's ages } 12-18 \text {, and interactions of each } \\
\text { with an indicator for welfare reform. The weak IV test statistic is a Kleibergen-Paap (2006) rank statistic. }\end{array}$} \\
\hline
\end{tabular}

